\title{
THE RELATIONSHIP BETWEEN MEDICATION ADHERENCE, HEALTH LITERACY AND SOCIAL SUPPORT NETWORK IN THE HYPERTENSIVE EMERGENCY DEPARTMENT PATIENT
}

\author{
A Dissertation \\ presented to \\ the Faculty of the Graduate School \\ at the University of Missouri-Columbia \\ In Partial Fulfillment \\ of the Requirements for the Degree \\ Doctor of Philosophy \\ by \\ BENJAMIN L COE \\ Dr. Maithe Enriquez and Dr. Gregory Alexander, Dissertation Supervisors \\ JULY 2020
}


(C) Copyright by Benjamin L Coe 2020

All Rights Reserved 
The undersigned, appointed by the dean of the Graduate School, have examined the dissertation entitled

THE RELATIONSHIP BETWEEN MEDICATION ADHERENCE, HEALTH LITERACY AND SOCIAL SUPPORT NETWORK IN THE HYPERTENSIVE EMERGENCY DEPARTMENT PATIENT presented by Benjamin Coe, a candidate for the degree of doctor of philosophy, and hereby certify that, in their opinion, it is worthy of acceptance.

Dr. Maithe Enriquez

Dr. Gregory Alexander

Dr. Laurel Despins

Dr. Glen Cameron

Dr. Phillip Rohde

Dr. Chelsea Deroche 


\section{DEDICATION}

I would like to dedicate this dissertation to my family, 21 years of college and you have supported me on so many levels throughout all of it. Through the triumphs and defeats, the bounds forward and the many stumbling blocks along the way, I could not have done this without you.

Additionally, to the providers, nurses, and staff of University of Missouri Emergency Department. So many of you have been so much a part of my journey and there to assist me when I needed help whether emotional, academic, or personal. I am truly thankful for so many of you that are more than just friends but are in actuality an additional bonus family to me. 


\section{ACKNOWLEDGEMENTS}

I would like to thank my committee over the years that I have been working on my degree even throughout all of its changes across the course of my academic career. Drs. Ruppar, and Kraus who moved on to positions guiding students at other institutions your advice and guidance were helpful during your tenure on my committee.

To Dr. Alexander, your willingness to step in and continue guiding me through my process and pulling me back on track when I would stray was immensely helpful, I wish you all the success possible in your new position and know that you will continue to make Mizzou proud to call you one of our own.

To Dr. Cameron, Dr. Deroche, Dr. Despins, and Dr. Rohde. Your availability to come onto my committee and join us on my pathway to completing my degree cannot be overlooked, for your timely additions to my committee allowed my progression to continue and my research to be conducted.

To Dr. Enriquez, you have been on this journey with me from the beginning, and given me opportunities for educational, service, and international growth that I never in my dreams would have imagined having the opportunity to be a part of. I am truly humbled by your knowledge and giving spirit. I am so eternally grateful for all you have provided for me. 


\section{TABLE OF CONTENTS}

ACKNOWLEDGEMENTS .................................................................................. ii

LIST OF ILLUSTRATIONS ......................................................................... vi

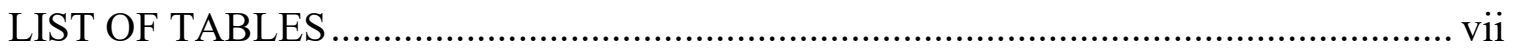

NOMENCLATURE ...................................................................................... viii

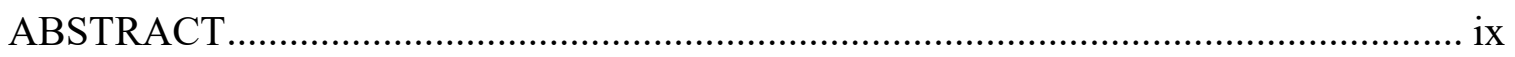

Chapter

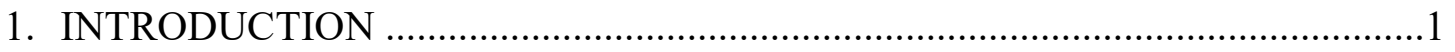

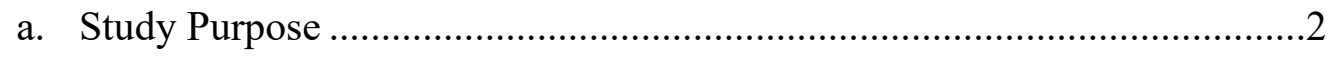

b. Implications for Research .................................................................

c. Aims and Research Questions .......................................................

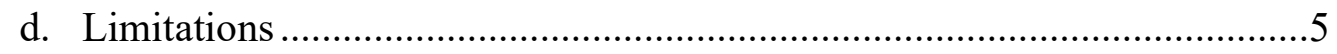

2. REVIEW OF THE LITERATURE .............................................................. 6

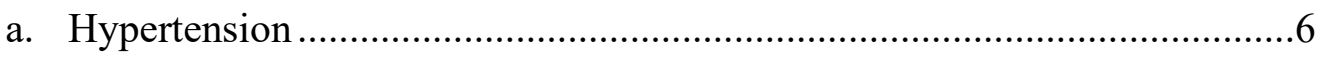

i. Definitions and Diagnosis................................................. 6

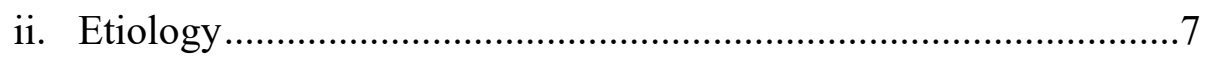

iii. Current Management ................................................................... 7

iv. Significance.......................................................................

b. Medication Adherence .............................................................. 9

i. Barriers that Affect Medication Adherence..................................10

ii. Significance of Medication Adherence to the Priority Population 12

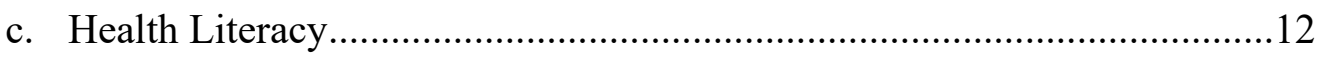

i. Significance of Health Literacy to the Priority Population............14

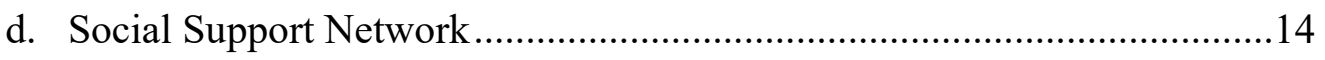

i. Familial Support.................................................................. 16 
ii. Neighbor or Friend Support .........................................................16

iii. Governmental/Non-Governmental Organization Support..............17

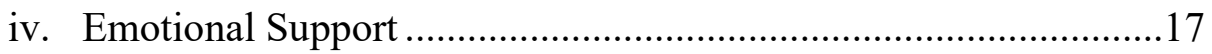

v. Financial Support ....................................................................17

vi. Significance of Social Support Networks for the Priority

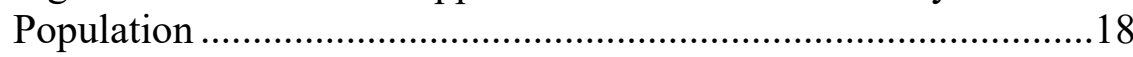

e. Conducting Research in the ED Setting.......................................................18

f. Guiding Framework …………………………………..........................19

g. Significance of the Dissertation Study........................................................20

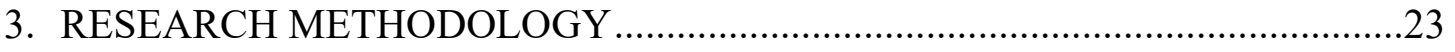

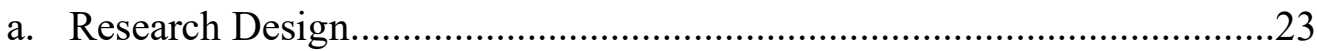

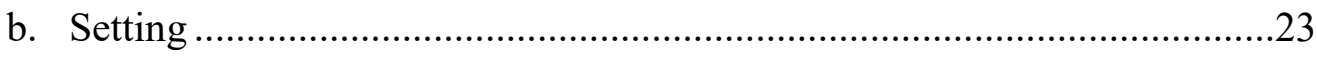

c. Sample

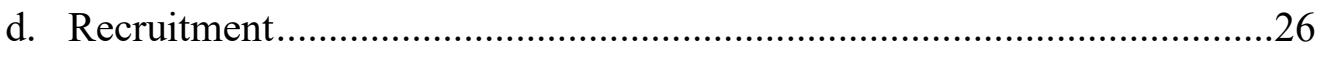

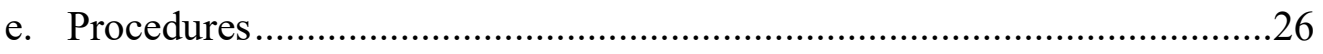

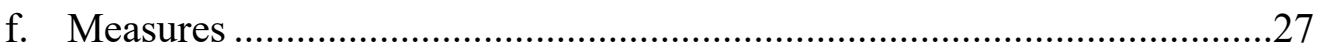

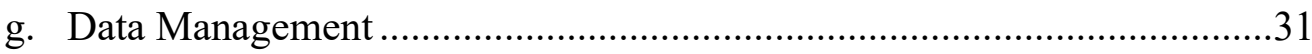

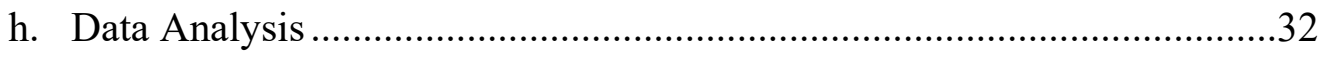

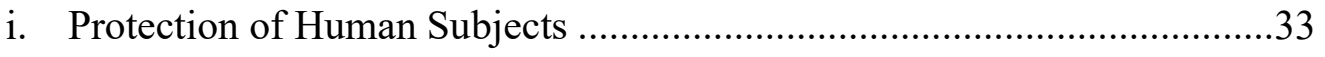

j. Data Safety and Monitoring ...........................................................................

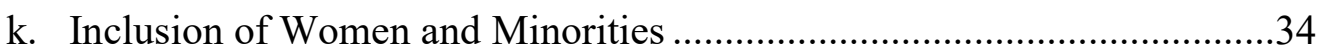

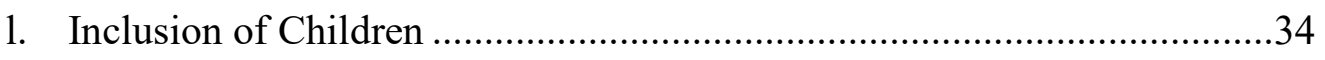

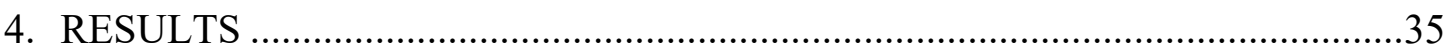

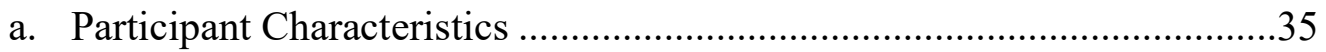

b. Relationship between Medication Adherence and Demographic / Health

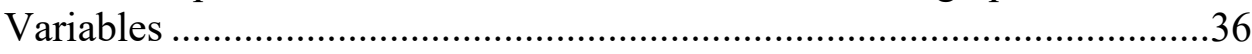


c. Relationship between Health Literacy and Demographic/Health Variables

d. Relationship between Social Support Network and Demographic/Health Variables

e. Relationship between Medication Adherence, Health Literacy and Social Support Network ...................................................................... 38

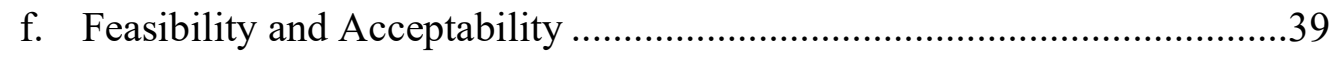

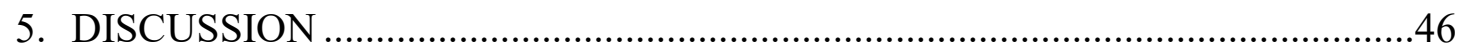

a. Implications for Future Research ...................................................50

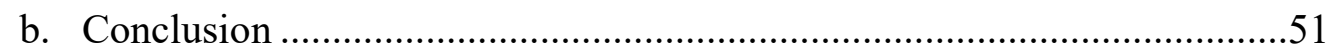

\section{APPENDICES}

Appendix A Demographic Survey ..........................................................53

Appendix B Basel Assessment of Adherence to Immunosuppressive medications

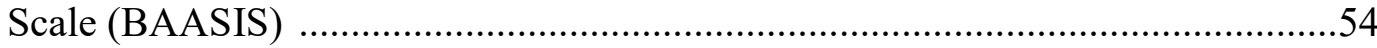

Appendix C Health Literacy Skills Instrument - Short Form (HLSI-SF) .............55

Appendix D Berkman Social Network Scale (BSNS) .......................................64

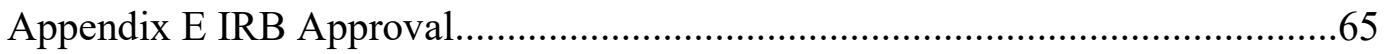

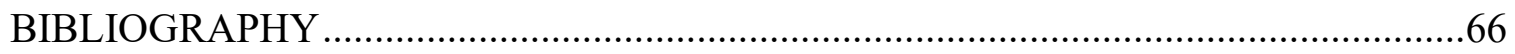

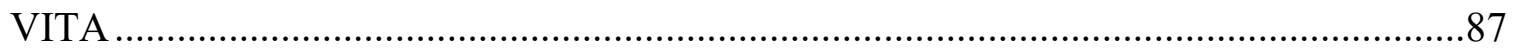




\section{LIST OF ILLUSTRATIONS}

$\begin{array}{lll}\text { Figure } & \text { Page }\end{array}$

1. Theoretical framework informing the need for research.......................................20

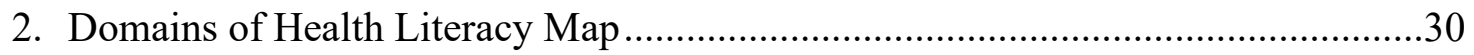




\section{LIST OF TABLES}

Table

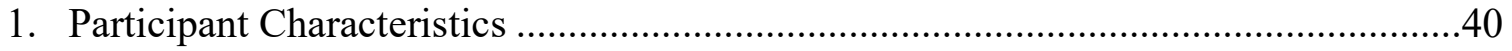

2. Medication Adherence, Health Literacy, Social Support Network Scores..................42

3. Relationship Between Medication Adherence, Health Literacy and Social Support

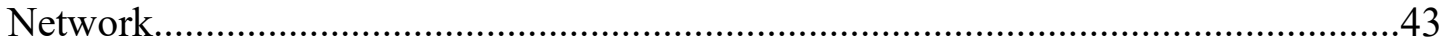

4. Relationship Between Medication Adherence and Demographic Variables..............43

5. Relationship Between Health Literacy and Demographic Variables .........................44

6. Relationship Between Social Support Network and Demographic Variables............44

7. Logistic Regression of demographic and variables of interest to Medication

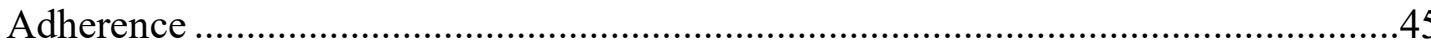




\begin{tabular}{ll} 
Abbreviation & Elaboration of Term \\
ACA & Affordable Care Act \\
AHA & American Heart Association \\
BAASIS & Basel Assessment of Adherence with Immunosuppressive Medication Scale \\
BSNS & Berkman Social Network Scale \\
CDC & United States Centers for Disease Control and Prevention \\
CI & Confidence Interval \\
ED & Emergency Department \\
HLSI-SF & Health Literacy Skills Instrument - Short Form \\
HTN & Hypertension \\
IMB & Information, Motivation, Behavioral Skills Model \\
IRB & Institutional Review Board \\
MUHC & MU Health Care \\
NGO & Non-Governmental Organization \\
PCP & Primary Healthcare Provider \\
PI & Principal Investigator \\
SBP & Systolic Blood Pressure \\
SPSS & Statistical Packet for the Social Sciences \\
\hline
\end{tabular}




\begin{abstract}
Hypertension (HTN) is a major risk factor for the development of heart disease, which is the number one cause of death in the United States (U.S.). The Affordable Care Act of 2010 (ACA) led to a significant increase in emergency department (ED) visits: up to $20 \%$ of visits are considered as avoidable. Many patients present to EDs with uncontrolled chronic health conditions, such as HTN, which can be successfully managed in the outpatient setting. Factors contributing to the large volume of patients that present to the ED with uncontrolled HTN has been understudied.

This cross-sectional study examined relationships between selected demographic and health variables, medication adherence, health literacy and social support network among adults $(\mathrm{n}=50)$ with HTN that presented to the ED. Participants were predominantly male (56\%), 41-60 years old (46\%), and Caucasian $(60 \%)$. Only $36 \%$ of participants were adherent to their HTN medications, $42 \%$ had adequate health literacy, and $38 \%$ perceived high levels of social support. The variable with the strongest correlation to medication adherence was last primary care provider (PCP) visit $(-0.473$, $\mathrm{p}<0.001$ ). However only $54 \%$ of participants had seen a PCP over the last 6 months. Increasing PCP visits and reducing avoidable ED visits has the potential to improve chronic disease health outcomes and reduce health care costs. This study has provided evidence that it is both acceptable and feasible to perform research in the ED setting that addresses chronic health conditions, such as HTN. Findings from this study may be used to inform novel ED interventions that can help adults to better manage their chronic health conditions, such as HTN, outside of the acute care setting.
\end{abstract}




\section{CHAPTER ONE: INTRODUCTION, PROBLEM, AND SIGNIFICANCE Introduction}

Hypertension (HTN) is a chronic health condition that is of growing health concern across the world, due to the associated increased risk for cardiovascular and cerebral events (Bobrow et al., 2016). Cardiovascular events are the leading cause of death in the United States and HTN is the number one contributing risk factor for heart disease and cerebral vascular accidents (CDC, 2016). With the recent expansion in the criteria for diagnosis of HTN by the American Heart Association (AHA), the number of HTN cases is expected to grow to greater than 103 million (Wald et al., 2018). HTN and its related co-morbidities account for 410,000 deaths and at a cost of $\$ 48.6$ billion per year (CDC, 2016). Treating HTN to achieve blood pressure (BP) control is critical to enhancing cardiovascular health outcomes (CDC, 2016; Whelton et al., 2017). However, only $20-50 \%$ of all individuals diagnosed with HTN worldwide have controlled BP and lack of adherence to antihypertensive medication is a major factor that contributes to this problem (Burnier \& Egan, 2019; CDC, 2016). New interventions must be developed to combat the problem of uncontrolled HTN in an effort to reduce the morbidity and mortality that it currently imposes. Individuals with uncontrolled HTN who are nonadherent with their antihypertensive medication regimen often become patients in the Emergency Department (ED) (Tocci et al., 2020). Hence, the ED could serve as an important point of contact for the implementation of novel interventions to help individuals with uncontrolled HTN (Prendergast et al., 2015). 


\section{Study Purpose}

Adequate medication adherence, health literacy and social support network have all been shown to improve health outcomes. Currently, characteristics regarding medication adherence, health literacy and social support network for patients that present to the ED with uncontrolled HTN have not been examined. A thorough literature search yielded no published research that specifically examined medication adherence, health literacy and social support networks of ED patients with a history of HTN. This lack of evidence provides a unique opportunity to develop novel interventions to address uncontrolled HTN in the ED setting. New strategies could improve health outcomes and reduce the risks associated with uncontrolled BP. Examining medication adherence patterns, health literacy rates, and levels of social support network could provide opportunities to develop tailored interventions to promote better HTN health outcomes among adults.

EDs are seen as facilities for rapid treatment, with minimal interruption, rather than a location for treatment and prevention of chronic disease (Vollbrecht et al., 2018). While it is true, EDs were designed to treat life threatening emergencies, the current trend of ED patients includes large numbers of patients seeking treatment for chronic conditions, non-life threatening injuries, and 'everyday sicknesses' that would typically be considered appropriate for the primary care setting (Balakrishnan et al., 2017). With the increase in this non-urgent type of ED visit, there is a need for research that addresses untreated and/or uncontrolled chronic health conditions. The purpose of this study was to: (1) examine the relationships between medication adherence, health literacy, and social support network among adults with HTN who presented to a mid-Missouri ED; and (2) 
evaluate the feasibility and acceptability of performing a study focused on a chronic health condition in the ED setting.

\section{Implications for Research}

The ED provides an opportunity to implement interventions that can address chronic health conditions, however the feasibility of conducting such studies has not been adequately explored. The ED has the potential to serve as a setting where interventions could be implemented to enhance BP control among individuals with uncontrolled HTN (Prendergast et al., 2015). In Missouri, the setting for the current study, there were 15,817 ED visits for patients with HTN in 2011 (Li \& Yun, 2013). The first step to developing a new intervention to assist this priority population with uncontrolled $\mathrm{BP}$, is to discern the characteristics of the hypertensive ED patient. Typically, the types of interventions that individuals receive in the ED setting for uncontrolled HTN consist of educational materials. Only in rare, or severely uncontrolled HTN situations, will some health care providers prescribe oral anti-hypertensive medications in the ED setting (Brody et al., 2015). ED providers are reluctant to treat patients with uncontrolled HTN in the ED setting as the health care providers' familiarity with the patient is typically low (Cho et al., 2015). Studies that have examined the likelihood that an ED physician would treat a patient with uncontrolled HTN, have found great variability by provider with regard to treatment plan (Brody et al., 2015; Cho et al., 2015).

It is important to note that HTN can negatively impact other existing co-morbid chronic conditions (Khangura et al., 2018). HTN is the leading cause of heart disease (Mozaffarian et al., 2015) and individuals with HTN and kidney disease have a 31\% increased chance of progressing to end stage renal failure (Mozaffarian et al., 2015). 
Furthermore, HTN is one of the leading causes of cerebrovascular events (Mozaffarian et al., 2015). However, a reduction of as little as a $10 \mathrm{mmHg}$ in systolic blood pressure (SBP) reduces the risk for cerebrovascular events by 41\% (Mozaffarian et al., 2015). HTN also plays a role in the progression of cirrhosis as elevated blood pressure can cause structural changes to the liver and may cause esophageal varices (Sinagra et al., 2014). However, reducing SBP by $12 \mathrm{mmHg}$ has been shown to eliminate the risk of esophageal varices (Matsumura et al., 2013; Prendergast et al., 2015; Sinagra et al., 2014). In the United States, the reliance by so many Americans on the ED for their health care, and the lack of chronic disease research focused on the ED setting, presents a unique opportunity to improve cardiovascular health outcomes by focusing on improving HTN care in the ED population.

\section{Aims and Research Questions}

Aim 1: To examine the relationship between medication adherence, health literacy, and social support networks among ED patients who are currently being treated for HTN.

RQ1: What are the relationships between medication adherence, health literacy and social support network?

Aim 2: To explore the feasibility and acceptability of conducting a cross sectional study in the ED setting with adults that present with an acute health problem, together with a history of HTN.

RQ2: Is it feasible and acceptable to conduct a cross-sectional study that addresses a chronic health condition (i.e. HTN), within a high-volume ED, regardless of the patient's reason for the ED visit? 
Hypothesis 1: Higher health literacy scores and higher social support network scores will be correlated with adherence to prescribed antihypertensive medications.

Hypothesis2: A cross-sectional study that focuses on a chronic health condition (i.e.

HTN) will be feasible and acceptable to conduct within a high-volume ED setting.

\section{Limitations}

Potential limitations of this study are primarily related to the setting. University of Missouri Health Care (MUHC) ED has a highly diverse population of patients due to its large catchment area and the multitude of specialty services offered at the facility. MUHC is an academic health center situated at a large land grant, Research I institution that attracts faculty and staff from around the world, as well as being a tertiary care provider for many specialized services. While the facility has a high diversity level, it is only one facility and, therefore, is not representative of the general population. Further, data about demographic and health characteristics for this study were collected through self-report. Self-reported data relies on the willingness of the participant to share personal, potentially private information (Polit \& Beck, 2020). In addition, self-reported data may contain response bias (Gorber \& Tremblay, 2016). 


\section{CHAPTER TWO: REVIEW OF THE LITERATURE}

\section{Hypertension}

HTN is a chronic clinical health condition that was first identified in 1895. Prior to this time, HTN was referred to as "hard pulse disease" and the thought was that the patient's blood volume needed to be reduced (Esunge, 1991). Identifying the condition was not possible until the invention of the sphygmomanometer (Swales, 1996). Further developments in measurement and identification of normotensive and hypertensive states developed with the discovery of Kortokoff sounds in the early 1900s (Kotchen, 2011). Over the years, many treatments and recommendations were developed prior to the advent of modern medicine, including bloodletting, leaches, and eating less food, eating more spinach, and avoiding anger and sexual intercourse (Esunge, 1991).

\section{Definition and Diagnosis}

The most recent definition of HTN was released by the American Heart Association in early 2017. HTN is currently defined as a repeated systolic BP greater than $130 \mathrm{mmHg}$ and/or a diastolic BP greater than $80 \mathrm{mmHg}$ (Whelton et al., 2017). It is reasonable to believe that in otherwise healthy individuals who are less than 40 years old who have BP measurements taken in health care clinics that are greater than $130 \mathrm{mmHg}$, but less than $160 \mathrm{mmHg}$ may be having "white coat syndrome" measurements and not true HTN (Whelton et al., 2017). In Patients with anxiety to medical care, white coat syndrome is the phenomenon of elevated BP in the presence of a medical provider (Zhang et al., 2019).

Diagnosis of HTN cannot come from one single BP measurement. Rather, a diagnosis should come from greater than two measurements taken at greater than two 
visits. Following in office measurements, HTN should be confirmed through comparison to out of office, home observations of BP (Whelton et al., 2017). Studies have been performed on immediate family members, twins, and more distant relatives resulting in a known $34-64 \%$ genetic link to HTN, however, there is no current genetic test for HTN available (Mill, 2019).

\section{Etiology}

There are many factors that may contribute to HTN, including excess weight, smoking, diabetes, dyslipidemia, low fitness, psychological stress, inadequate diet, and sleep apnea (Whelton et al., 2017). While the development of HTN is associated with a number of risk factors, it is often a combination of such factors, rather than any single factor, that leads to HTN (Whelton et al., 2017).

\section{Current Management}

Treatments for HTN vary based on individual risk factors, health care provider treatment preferences, and medication side effects. Initially, attempts to control HTN are often related to dietary and lifestyle behavior modifications. Decreasing sodium intake is the typical first line treatment modality for HTN (Papademetriou et al., 2018). Various other lifestyle changes are often recommended for patients with HTN. Among these are being active $>4$ days a week, eating a diet rich in fruits and vegetables, avoiding alcohol in excess, refraining from smoking and losing weight if the patient is obese (Ozemek et al., 2020). If dietary and lifestyle modifications are not successful at reducing BP, medications are usually added. Typical front line medications for HTN are angiotensin converting enzyme (ACE) inhibitors (G. Marazzi, 2018), diuretics, and calcium channel 
blockers (Papademetriou et al., 2018). Beta blockers can also be added for additional HTN management (Papademetriou et al., 2018).

ED interventions for patients with HTN usually consist of educational materials, however in rare and severe situations some ED health care providers will prescribe oral anti-hypertensive medications (Brody et al., 2015). ED physicians are reluctant to treat patients in the ED setting as the physician's familiarity with the patient is typically low (Cho et al., 2015). Researchers distributed a survey to ED providers during rounds to determine at what threshold they would prescribe home medications for patients with HTN in their ED that they were discharging (Cho et al., 2015). The authors showed that roughly half of the providers had a set value for prescribing medications and that patient co-morbidities affected their decisions (Cho et al., 2015). In comparison, another retrospective study found that ED providers who treated asymptomatic HTN did so for roughly $35 \%$ of patients and that providers appeared to have their own preferences with regard to medications selected for treatment (Brody et al., 2015).

\section{Significance}

HTN is an important chronic health condition that contributes to the risk for heart disease and cerebral vascular accidents. Moreover HTN impacts all parts of the U.S. population (Centers for Disease Control and Prevention (U.S.), 2016). In 2014, the most recent year with available data, 75 million people in the United States had HTN, which is approximately 1 in 3 Americans (CDC, 2016). In 2017, the American Heart Association (AHA) adjusted the ranges for the varying degrees of HTN. Reducing the "normal BP" to $<120 /<80 \mathrm{mmHg}$, defining elevated as $120-129 /<80 \mathrm{mmHg}$, and beginning grade $1 \mathrm{HTN}$ at 130/80mmHg (Whelton et al., 2017). With the 2017 changes in the guidelines for 
diagnosis and treatment of HTN by the AHA that number is expected to grow to over 103 million (Wald et al., 2018).

\section{Medication Adherence}

Prior studies on medication adherence in patients with HTN have shown a wide range of adherence levels (Burnier \& Egan, 2019). A meta-analysis from the last 20 years of published research on the medication adherence in patients with HTN (Burnier \& Egan, 2019). With medication adherence levels estimated anywhere between 20 and $50 \%$, there is, in turn, variance in patients' control of their disease (Burnier \& Egan, 2019). While this data is of use, studies have focused on medication adherence, and HTN control in outpatient, inpatient, and long-term care setting. No studies were located that focused on the population of patients with HTN that presents to the ED setting.

There are several factors that increase the importance of medication adherence when examining patients with HTN. Developing a better patient outcome is the first and foremost important factor for increasing medication adherence (Matsumura et al., 2013; Mill, 2019; Papademetriou et al., 2018). Non-adherence to antihypertensive medications alone is associated with 89,000 premature deaths annually (Cutler \& Everett, 2010). In addition, uncontrolled HTN increases ED visits and admissions to the hospital (Cutler \& Everett, 2010). Multiple studies have shown that adherence to medications increases quality of life, reduces medical costs, and decreases patient readmission rates to hospitals (Bailey et al., 2014; Cutler \& Everett, 2010; Roebuck et al., 2011; Toy et al., 2011). As part of the Affordable Care Act of 2010, new mandates were established that require reduction in readmission for multiple chronic health conditions as a measure of service and quality of care (Centers for Medicare and Medicaid Services, 2015b). The Centers 
for Medicare and Medicaid Services (CMS) recognize that decreasing readmissions for conditions such as HTN, Diabetes Mellitus, Heart Disease, and Chronic Obstructive Pulmonary Disease (COPD) among others shows improvements in patient outcomes and correlates to better healthcare from the facility (Centers for Medicare and Medicaid Services, 2015b). Better medication adherence and symptom control will reduce hospital readmissions (Centers for Medicare and Medicaid Services, 2015b). With reimbursement of costs tied to readmission, it is in hospitals' best interest to increase the medication adherence of their patients in order to provide more income for the hospital (Centers for Medicare and Medicaid Services, 2015a).

\section{Barriers to medication adherence}

When examining medication adherence, one first must understand major barriers that inhibit adherence. There are known barriers to medication adherence that can be addressed by interventions. Among the many barriers, the most often cited are the cost of medications (Bailey et al., 2014; Hunter et al., 2014; Marcum et al., 2013; Mazer et al., 2011), the side effects of those medications (Dibonaventura et al., 2012; Nakhutina et al., 2011), and the dosing regimen, both complexity and length, associated with taking medications (Cutler \& Everett, 2010; Toy et al., 2011).

Cost of medication is often isolated as a cause for medication non-adherence, especially when examining vulnerable populations such as the poor, elderly, and homeless (Bailey et al., 2014; Hunter et al., 2014; Marcum et al., 2013; Mazer et al., 2011). When examining the Medicaid population of Tennessee, patients reported that cost was a major concern (Bailey et al., 2014). The authors of the study also found that within the Medicaid population of Tennessee being male, black, obese, using substances, 
or having mental illness were all co-factors. However, each factors could also be contributing to reduced income (Bailey et al., 2014). The homeless populations of Ottawa, Canada as well as the vulnerably housed (i.e. those who were homeless within the last year) were found to be concerned about the cost of their medications (Hunter et al., 2014). Individuals with unstable housing were also concerned about their ability to appropriately store their medications (Hunter et al., 2014). Older adults often live on a fixed income, as a result the cost of medication becomes a concern. In a populationbased observational study of older adults ages 70-79, findings showed that older adults would often split doses, or skip them in order to make medication refills last longer (Marcum et al., 2013).

Side effects of medications have also been shown to be a major deterrent to medication adherence, and has been reported as the direct reason that patients quit taking their medication up to $33 \%$ of the time (Hunter et al., 2014). Three primary classes of medication side effects appear to have major roles in negatively impacting adherence. Those classes are extrapyramidal (Menzin et al., 2014; Rummel-Kluge et al., 2012), metabolic (Dibonaventura et al., 2012), and sexual side effects (Dibonaventura et al., 2012).

Finally, the dosing regimen of prescribed medications has been shown to have a strong impact on adherence. As the number of medications, and the number of times a person is required to take each medication per day increases, their adherence to the regimen decreases (Bailey et al., 2014). Regimen complexity has been shown as a barrier to medication adherence in many studies across a wide spectrum of diseases, including HTN (Cramer, 2004), HIV/AIDS (Ickovics \& Meade, 2002; Stone et al., 2001). In a 
study looking at the medication usage data from employees of multiple Fortune 500 companies who had COPD showed that over time, increasing the number of doses significantly reduced adherence (Toy, et al., 2011). A caveat to this study on COPD medication adherence however is that the medication adherence was estimated based on pharmacy fill data rather than a discussion with, or report from the patients analyzed. While pharmacy fill data are often used to determine adherence, this method hinges on the assumption that a person who has refilled a medication is actually taking it (Toy et al., 2011). In contrast, rather than placing all of the responsibility on the individual patient to ensure medication adherence, the suggestion has been made that prescribers should bear some through improved communication and ensuring that regimens are as uncomplicated as possible (Cutler \& Everett, 2010).

\section{Significance of Medication Adherence to the Priority Population}

Medication adherence plays an important role in the management of chronic health conditions. However, there are many factors each exert influence on an individual's medication adherence. Therefore, interventions must be tailored to increase efficacy (Halladay et al., 2017; Wannasirikul et al., 2016; Whelton et al., 2017). With the increasing reliance on EDs as primary care settings, it is imperative that researchers develop medication adherence interventions specifically for this setting.

\section{Health Literacy}

Medication adherence is not as simple as patients taking their medications as directed. Medication adherence has also been found to require an adequate level of health literacy, which is an understanding about one's health condition and the recommended 
treatment (Kale et al., 2015). Health literacy is an important factor in medication adherence and often determines engagement in self-care behaviors and the promotion of positive health outcomes in chronic health conditions (Dworkin et al., 2018). If individuals do not understand the rationale for taking prescribed medications, it can negatively impact both their adherence and conversations with their providers about treatment options. This lack of understanding is demonstrated in the ED especially when health care providers are attempting to illicit a medical history for a patient, and the patient states that they have no health problems but are later found to indeed have chronic health conditions with a history of prescribed medications (Cho et al., 2015). The lack of health literacy can result in the belief that one does not have a health problem, for example HTN, because one is taking medication for the condition. In other words, the chronic and lifelong nature of the diagnosis is not understood (Neter \& Brainin, 2019).

Multiple studies have targeted specific chronic health conditions to assess the correlation between health literacy about the condition and medication adherence to treat the condition. Studies have focused on asthma (O'Conor et al., 2015), COPD (Kale et al., 2015), diabetes (Thurston et al., 2015), and HIV disease (Pellowski \& Kalichman, 2016), among others. However, few prior studies have been performed to examine the correlation between health literacy and adherence to treatment in the general population (Sawkin et al., 2015). No studies were located that focused on individuals presenting to the ED and their health literacy about their chronic health conditions. Of the studies that have been completed on the general population, none were located that focused on the Midwest United States population. 


\section{Significance of Health Literacy to the Priority Population}

There is a need to assess the health literacy in the ED population with regard to underlying chronic health conditions. Such information would be helpful in order to determine where to begin addressing issues with regard to poorly controlled health conditions and medication adherence, as they are so intimately intertwined. When considering health literacy, the increased reliance on the ED as the source for primary care cannot be overlooked. Steps must be taken at every ED visit to assess and enhance health literacy in the population as a whole. Past studies have shown that simply providing more written documentation at discharge from the ED does not adequately improve health literacy (McCarthy et al., 2013). It is important to consider new strategies for increasing health literacy in order to improve overall health and well-being. In this program of research, the ultimate aim is to improve health literacy in an effort to reduce the morbidity and mortality associated with uncontrolled HTN.

\section{Social Support Network}

Social support network is an expanding field of research and was defined by Sheldon Cohen (1992) as consisting of three constructs: social networks, perceived social support and support behaviors. Social networks is the existence, quantity and type of relationships. Perceived social support is the function of social relationships. Finally, supportive behaviors are the mobilization and receipt of behaviors intended to aid persons in the face of stressful events. (Cohen, 1992). With studies dating back into the late 1950s, researchers have recognized the influence of social support on the ability to adhere to medications for chronic health conditions (Adisa et al., 2017; Berkman \& Syme, 1979; 
Mill, 2019; Shallcross et al., 2017). However, despite the agreement that social support is an important determinant of adherence, its exact role remains debated (Lu et al., 2019; Spikes et al., 2019; Wu \& Sheng, 2019).

A recent study found that the most significant factor for medication adherence in hypertensive patients is the size of their social support network (Shallcross et al., 2017). In Shallcross et al., (2017) the authors examined patients with apparent treatment resistant HTN. This population included patients who were on greater than three classes of anti-hypertensive medications, or greater than three with the addition of a diuretic. This study was a part of the Jackson Heart study that sought to determine the causes of increased risk of cardiovascular disease in the African American population of Jackson, MS. In total 5,306 participants underwent the screening from 2000-2004. Out of all of the factors that the authors examined in the study, social support network was the only significant factor in reducing apparent treatment resistant HTN. For each additional unique social contact, men and women reduced their chances of having treatment resistance by $19 \%$ and $13 \%$ respectively (Shallcross et al., 2017).

Some of the debate about the role of social support network and medication adherence, centers around the type of support given and how that support mediates adherence. The source and type of support has been shown to impact adherence (Adisa et al., 2017; Wu \& Sheng, 2019). Social support can be provided in different forms, for example: familial support, neighbor/friend support, and governmental/ non-governmental organization (NGO) support (Adisa et al., 2017; Nyaaba et al., 2019; Wu \& Sheng, 2019). The support can also be directed in various manners: emotional support, physical support, and financial support (Adisa et al., 2017; Nyaaba et al., 2019; Wu \& Sheng, 
2019). The source and type of support both can have varying effects on adherence and treatment outcomes (Adisa et al., 2017; Mill, 2019; Nyaaba et al., 2019; Wu \& Sheng, 2019).

\section{Familial Support}

The most basic and easily recognized form of social support is familial support (Nyaaba et al., 2019; Padhy et al., 2016; Shallcross et al., 2017; Wu \& Sheng, 2019). Familial support is believed to influence self-efficacy for medication adherence and healthful behaviors through giving individuals "something to live for", or a sense of belonging and identity (Adisa et al., 2017; Aragão et al., 2017; Padhy et al., 2016). Familial support can take on various forms: emotional, physical, or monetary (Aragão et al., 2017; Nyaaba et al., 2019; Wu \& Sheng, 2019). Familial support's effect on adherence has been found to be stronger for men, as compared to women. One study showed that increasing the numbers of family members living within one house increased the likelihood that men would be adherent to their medications (Nyaaba et al., 2019).

\section{Neighbor or Friend Support}

In certain populations, neighbor and friend support have been found to be equal to or stronger predictors of individual adherence levels than familial support (Lu et al., 2019; Padhy et al., 2016; Wu \& Sheng, 2019). In studies where neighbor support was more effective than family support, it is important to note that the findings could have been impacted by the distance to family. For example, participant's children lived far from home. Hence, participants may have developed a support network based around their neighbors since they did not have family present in their lives (Wu \& Sheng, 2019). 


\section{Governmental/ Non-Governmental Organization Support}

Governmental or non-governmental organization (NGO) support has been identified as being the most desired, although the most difficult to attain (Adisa et al., 2017). Governmental, or NGO support, was found to be highly desired as they typically are offering monetary or physical support through opportunities to obtain treatments (Adisa et al., 2017). This preference towards monetary support could be related to cost and availability of medications. Reducing financial burden on the participant, enhanced the ability to access medications (Adisa et al., 2017).

\section{Emotional Support}

Emotional support and the feeling of belonging are noted as being key components of familial, friend and neighbor support (Adisa et al., 2017; Nyaaba et al., 2019; Padhy et al., 2016; Wu \& Sheng, 2019). The benefits of emotional support have been demonstrated by studies that find a link between social support and medication adherence, as related to HTN (Adisa et al., 2017; Aragão et al., 2017; Berkman \& Syme, 1979; Nyaaba et al., 2019; Padhy et al., 2016; Shallcross et al., 2017; Wu \& Sheng, 2019). One study, however, examined the impact of social support on different chronic health conditions (Aragao et al., 2017). Physical health conditions were found to have an inverse pattern of effect on social support, as compared to mental health conditions (Aragão et al., 2017).

\section{Financial Support}

With regard to preference for type of support, monetary or financial support was found to have a higher impact on adherence, than emotional or physical support (Aragão 
et al., 2017; Nyaaba et al., 2019; Wu \& Sheng, 2019). Financial support provides a person with the ability to access medications. However, while financial support does enhance access, however, solely having a medication does not ensure that one will take it (Cutler \& Everett, 2010).

\section{Significance of Social Support Networks for the Priority Population}

Research on social networks demonstrates mixed results (Nyaaba et al., 2019; Shallcross et al., 2017; Spikes et al., 2019). Various levels of social support have been reported in HTN medication adherence studies. Reasons for variation with regard to the impact of social support network may be related to the population being studied, the measure of social support used, the socioeconomic status of the participants, and/or the disease addressed in the study (Aragão et al., 2017; Lu et al., 2019; Nyaaba et al., 2019; Shallcross et al., 2017; Spikes et al., 2019). Differences with regard to the impact of social support network on medication adherence, in published studies, demonstrate the need to further examine the role of social support network and further demonstrates the complicated nature of medication adherence.

\section{Conducting Research Studies in the ED Setting}

When conducting any research study, a researcher must assess whether the study will be both feasible and acceptable. Feasibility and acceptability are often examined through looking at participation and completion rates (Strickland \& Stoops, 2018). Studies with excessive sample sizes are difficult to complete in EDs due to the variance of visit numbers and reasons for the visit (Nadia Hatmi, 2019; Smith \& Morley, 2015). In order to complete a study in an ED setting, the sample size must be small enough to allow for recruitment to occur over a reasonable amount of time (Smith \& Morley, 2015). A 
study must have an acceptable response rate to not skew the data (Saleh \& Bista, 2017; Stolzmann et al., 2019; Tyser et al., 2016). Lastly, in order to feasibly conduct a study, the condition must be frequently seen in the ED setting (Nadia Hatmi, 2019).

There have been multiple studies performed in ED settings throughout the country. Additionally, there are journals dedicated to the ED setting, for example Emergency Medicine and Emergency Nursing. Given these facts, it seems that it would both feasible and acceptable to perform studies focused on chronic disease research in the ED setting. However, a literature search was performed to locate HTN studies performed in the ED setting. Limited studies were found that specifically examined HTN patients that reported to the ED. Studies were located that examined patients in their primary care environment, those that had been admitted to the hospital, and whether or not patient had visited the ED (Brody et al., 2015; Burnier \& Egan, 2019; The SPRINT Research Group, 2015; Yannoutsos et al., 2017). At the onset of this dissertation study, no published studies were located that focused on the chronic health condition of HTN in the ED patient population.

\section{Guiding Framework}

The theoretical model guiding this study was the Information, Motivation, Behavioral Skills Model (IMB) of health behavior (see Figure 1) (Fisher et al., 2003). An assumption in this study, based on the IMB model, is that higher levels of health literacy aid adults in being more adherent to their medications by increasing understanding of health behavior information, health condition (i.e. HTN), and enhancing health behavior skills (e.g. how and when to take medications).Under the auspices of the IMB model, the 
health behavior of interest (i.e. improved BP control) can be accomplished through providing increased understanding of health information (i.e. increasing health literacy), and motivation (i.e. social support network) to engage in healthful behaviors and health behavioral skills (i.e. medication adherence).

By examining

measures of medication adherence, health literacy, and social support network for the priority population (i.e. adults with uncontrolled HTN), new interventions

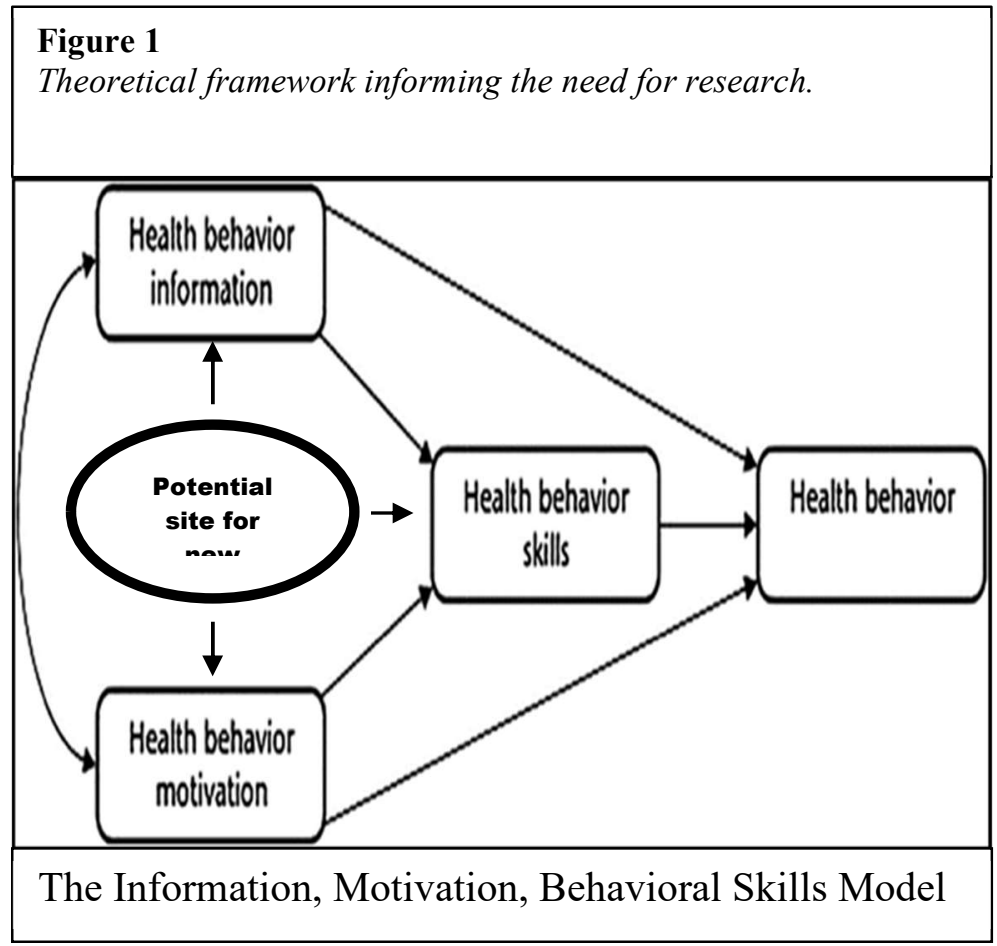
can be designed to change health behavior through theoretical models such as the IMB to improve HTN health outcomes. The motivation that individuals need to be adherent to their medication may come from many forms, in this study, the influence of social support network, is assumed to lead to a desire to remain a part of the community (Berkman \& Syme, 1979) and enhance medication adherence. Motivation can also come from other forms of support such as direct reminders to take medications, or reminders of positive and negative outcomes of adherence (Arora et al., 2015; Arora et al., 2014).

\section{Significance of the Dissertation Study}

This study aimed to better understand the factors contributing to the growing population of adults who present to the ED setting with uncontrolled HTN. Through a 
greater understanding of the variables of interest to this study, new interventions can potentially be developed to meet the needs of this priority population. Since the implementation of the Affordable Care Act (ACA) of 2010, EDs are seeing greater numbers of patients every year (Lin et al., 2018). Many of these patients present to the ED with chronic health conditions, like HTN, that are uncontrolled. On average, across the eight year period from 2006 to 2014 , EDs saw their visits increase by $18.3 \%$ (Lin et al., 2018). Over $\$ 328.1$ billion was spent on ED visits nationwide and up to $20 \%$ of ED visits are considered avoidable (Jaffe et al., 2018). Eliminating those avoidable visits has been estimated to potentially save $\$ 60$ billion per year (Jaffe et al., 2018). There is a need to develop interventions that can help people who present to the ED with uncontrolled chronic health conditions, such as HTN. Within the ED setting, 'treat'em and street'em medicine" was at one time the culture (Vollbrecht et al., 2018, p. 402), however, there is a need for reshaping of the ED care paradigm. The culture of emergency medicine and nursing is being redirected to reduce the number of visits from "super-utilizers" (i.e. those patients seen in the ED more than four times per year) by improving management of their chronic health conditions, including enhancing their medication adherence (Sampson et al., 2017).

The reality of healthcare in the $21^{\text {st }}$ century is that fewer patients are seeing a primary care provider, now more than ever before (Ganguli et al., 2020). In the period between 2008, before the implementation of the ACA, and 2017 primary care visits dropped by $24.2 \%$. Furthermore, the proportion of adults without a single primary care visit rose by $8.3 \%$ (Ganguli et al., 2020). These patients were instead seen in EDs across the country. In the same period of time, another study found that $68.2 \%$ of all ED visits 
were self-referred and $99.7 \%$ of those visits were patients arriving by private vehicle (Brasseur et al., 2020). These studies begin to highlight the problem of the ED serving as primary care for many people. This new, greater reliance on the ED for primary care demonstrates the need for research that can help people successfully manage their chronic health care conditions in the ambulatory community setting. 


\section{CHAPTER THREE: RESEARCH METHODOLOGY}

\section{RESEARCH DESIGN}

This dissertation study is the first step in a program of research that aims to develop medication adherence interventions for adults with uncontrolled chronic health conditions. Specifically, this program focuses on finding novel interventions to implement in the ED setting that can help individuals better adhere to prescribed medication regimens. The current cross-sectional study utilized a convenience sample to examine the relationship between medication adherence, health literacy, and social support network among adult patients who presented to an ED and had an active diagnosis of HTN. This study utilized three independent survey instruments, the Basel Assessment of Adherence with Immunosuppressive Medication Scale (BAASIS) (De

Bleser et al., 2011) to measure medication adherence, the Health Literacy Skills Instrument - Short Form (HLSI-SF) (Bann et al., 2012) to measure health literacy, and the Berkman Social Network Scale (Berkman \& Syme, 1979; Shallcross et al., 2017) to measure social support network. Relationships between selected demographic variables (i.e. gender, ethnicity, education, and income), medication adherence, health literacy and social support network scores were examined. The study was approved by the MU Health Sciences IRB, project number 2016741.

\section{Setting}

The study was conducted at University of Missouri Health Care (MUHC) ED. The MUHC ED has 60 beds and is situated within an academic medical center in MidMissouri, United States. The facility is a tertiary care center that is certified as a Level 1 trauma center, Level 1 stroke center, Level 1 cardiac center, Level 4 epilepsy center and 
the only burn center in Mid Missouri and includes dedicated facilities for orthopedics and women's and children's services. As an academic medical center with complement of specialty medical fields, the facility offered a varied patient population from which to sample. The ED has 34 board certified emergency physicians as well as several Physician Assistants and Nurse Practitioners. Additionally, the ED has an Emergency Medicine Residency Program to train new providers both at the Physician and mid-level provider certifications. The ED is open 24 hours a day, 365 days a year and sees an average of 170 patients per day (range of 100-215).

Missouri as a state has a total population of 6,090,062, with 96.4 males for every 100 females. Of the total population, 4.7 million Missourians are over the age of 18, and 982,000 are over the age of 65 . With regard to racial/ethnic diversity, the state reports 82.8\% Caucasian, 11.6\% Black/African American, 3.5\% Hispanic/ Latino, and 1.6\% Asian. State level data were not available for insurance status (Census Bureau (U. S.), 2020). HTN affects members of all races and age groups, however, being of African American descent and being greater than 65 years of age increase the likelihood that you will be hypertensive (Li \& Yun, 2013).

The state's two major urban areas are situated along the largest East - West corridor at opposite sides of the state. Kansas City and St. Louis (i.e. Jackson and St Louis Counties respectively) both have large urban populations and are surrounded by suburban towns. There are five other major suburban locations spread across the state including Boone County, where the study was conducted. Each of these areas has a suburban center surrounded by rural areas and uninhabited land. Additionally, the state is mostly rural and health care coverage is sparse (Census Bureau (U. S.), 2020). Rural 
Pemiscot county, in extreme South Eastern Missouri, has more than double the unemployment rate of the state, higher uninsured rate, higher disability rate, and a significantly lower median wage when compared to the state as a whole (Census Bureau (U. S.), 2020). Additionally, Southeast Missouri is less racially diverse, and suffers from stagnant growth as only 9 new properties were built throughout all of 2019 compared to nearly 18,000 throughout the state (Census Bureau (U. S.), 2020).

\section{Sample}

The convenience sample consisted of 50 adults that presented to the MUHC ED with an active diagnosis of $\mathrm{HTN}$, defined as a BP greater than 130/80 $\mathrm{mmHg}$ (Wald et al., 2018), and taking at least one antihypertensive medication. The sample of 50 was based on a power analysis of the study variables associated with the aims (Guenther, 1977). Power analysis was based on correlations between variables. A sample size of 46 achieves $80 \%$ power to detect a difference of $\rho=0.4$ using a two sized hypothesis test with a significance level of 0.05 . Logistic regression analysis is powered assuming $54 \%$ adherence in the population with an estimated $40 \%$ of participants having adequate health literacy in the sample. A logistic regression on a binary response variable (medication adherence) on a binary independent variable (adequate health literacy) with a sample size of 49 observations (of which $40 \%$ have adequate health literacy) achieves $80 \%$ power at a 0.05 significance level to detect a change in the probability of medication adherence from the baseline value of 0.54 to 0.9 . This change corresponds to an odds ratio of 7.6. Study participants were 18 years of age and older and were responsible for their own decisions for health care and their own medication administration. Participants were alert, and oriented to person, place, time, and events; with a Glasgow Coma Scale of 15. Patients 
were excluded if they deferred their responses to a family member, were not willing to complete the survey or if they had previously been administered the study instruments by their own admission.

\section{Recruitment}

Participants were recruited from adults presenting to MUHC ED for treatment of any complaint other than those considered to be a time critical diagnosis such as trauma, stroke, or heart attack. Participants were screened for inclusion criteria by the Principal Investigator (PI), who contacted the primary nurse in the ED to determine if the patient had a history of HTN and at least one HTN medication in their medication list. Identification of patients occurred once the patient had been placed in a room and assessed by the primary nurse and provider to reduce disruptions to care while in the ED. Once a potential patient was identified, the patient was approached by the PI to secure informed consent to participate in the study. Participants participated in the study voluntarily and were not offered any incentive to complete the study.

\section{METHODS}

\section{Procedures}

Participants in the study were administered three (3) instruments for assessment of medication adherence, health literacy, and social support network. In addition, patients were asked to complete a demographic questionnaire. After completing informed consent, participants completed the survey instruments using a handheld computer device (i.e. tablet) with the surveys pre-loaded. Participants answered the demographic questions first and then moved directly into the survey questions. The instruments were completed in the following order for each participant: medication adherence, health literacy and 
social support network. The demographic questionnaire and the three survey instruments totaled 27 questions for each survey respondent. Following completion of the survey by the participant, the tablet was returned to the PI who then recorded the reason for visit and obtained the participant's initial BP reading, on presentation to the ED, from the primary nurse. Data were downloaded from the tablet into an excel file for analysis. In order to develop the survey administration, multiple iterations were performed using several formats to develop the final presentation of survey instruments used by participants. Initial plans for the study were to keep data storage local and develop the survey tool within the tablet computer used for taking the survey. The first attempts were made utilizing Microsoft $^{\mathfrak{O}} 365$ Access $^{\mathcal{O}}$. This attempt while visually pleasing and would have allowed the data to be collected directly into a spreadsheet for analyzing was not able to produce a form long enough to complete all of the questions without intervention from the researcher multiple times throughout administration. The second attempt was made using quizlet, a free online service to develop flashcards and quizzes. This method was quickly abandoned as the data could not easily be secured and ensured that they would be protected from interference. The last method attempted was the use of the University of Missouri's (MU) Qualtrics Portal. Qualtrics is free to use for MU students and staff. The survey was designed as an online quiz which then placed the answers by participants into a downloadable spreadsheet. Images and web-based links in the survey were tested to ensure that they were readable by multiple individuals prior to opening the survey, and that all links worked repeatedly without failing to direct to the appropriate website. The survey was secured with password protection ensuring that only the researcher could open the survey to allow individuals to participate. 


\section{Measures}

This study utilized three instruments, that have been used extensively in previous research studies, to examine medication adherence, health literacy, and social support networks. A demographic survey, created by the PI, was used to collect demographic data.

Demographic data were collected by self-report for the study and included: age, race, gender, marital status, level of education, insurance status, and time since last visit with a primary care provider (See Appendix A). Participant age was collected as a categorical variable with the participant selecting the age category that matched current age. Options were provided within gender for participants who were non-gender binary. Multiple selections were allowed for race and insurance status.

The Basel Assessment for Adherence to Immunosuppressive Medication Scale (BAASIS) scale (see Appendix B) was used to measure medication adherence by selfreport. The BAASIS is a survey composed of four questions that assess four domains of medication adherence (i.e. Taking, Timing, Drug Holidays, and Dose Reduction). Each of the questions measures these variables on a Likert Scale (range 0-5) with zero being never and five being daily. Any score on any domain other than zero is scored as nonadherent (De Bleser et al., 2011; Dobbels et al., 2010; Kerr et al., 2005; Schafer-Keller et al., 2008). The BAASIS is also known as the Siegel Scale and has been utilized in HTN, HIV and immunosuppression medication adherence studies (De Geest et al., 2014; Kerr et al., 2005; Schafer-Keller et al., 2008). In studies using the BAASIS and immunoassays of circulating blood levels of medications, there were significant correlations across all questions ranging from $r_{\text {rho }}=-0.133(p<0.05)$ to $r_{r h o}=0.331(p<0.05)($ Schafer-Keller 
et al., 2008). The BAASIS questionnaire relies on negative reporting to reduce the urge to please the researcher with positive responses (De Bleser et al., 2011).

The selection of the BAASIS as the medication instrument of choice was due to several factors. As the study was using self-report, it was important to select a tool that could provide accurate self-report information. As the BAASIS relied on negative reporting, it provided a method to reduce potential bias due to want to please the researcher (De Geest et al., 2014). Additionally, the BAASIS had already been utilized in HTN, and shown to be accurate when compared to serum drug levels which verifies its utility in this study (De Geest et al., 2014).

The Health Literacy Skills Instrument - Short Form (HLSI-SF) was used as the measure of health literacy (Appendix C). The HLSI-SF is a 10 question self-report survey which measures health literacy across four domains of health literacy (Figure 2) (Bann et al., 2012). A score of 7 or higher is considered adequate health literacy (Bann et al., 2012). Development and implementation of the instrument showed that the question most often missed in the instrument was a numeracy question where participants needed to calculate how much saturated fat was in a serving, in contrast the question most often answered correctly was related signs of a stroke (Bann et al., 2012). The HLSI-SF measures four domains of health literacy; print literacy (ability to read and understand English), numeracy skills (ability to calculate simple math), oral literacy skills (ability to understand and process information heard), and information seeking skills (ability to 
acquire information through the internet) (Bann et al., 2012).

Figure 2

Domains of Health Literacy Map.

Measurements are attained by self-

report as the participant answers

comprehensive questions based on

material (i.e. a hospital map, a

medication administration record, and

a nutrition label for example)

presented to the patient. Testing

across all four domains of health

literacy gives a better estimate of the

functional literacy of the patient,

rather than their ability to pronounce

words on a page. For the purposes of

this study, only the total health

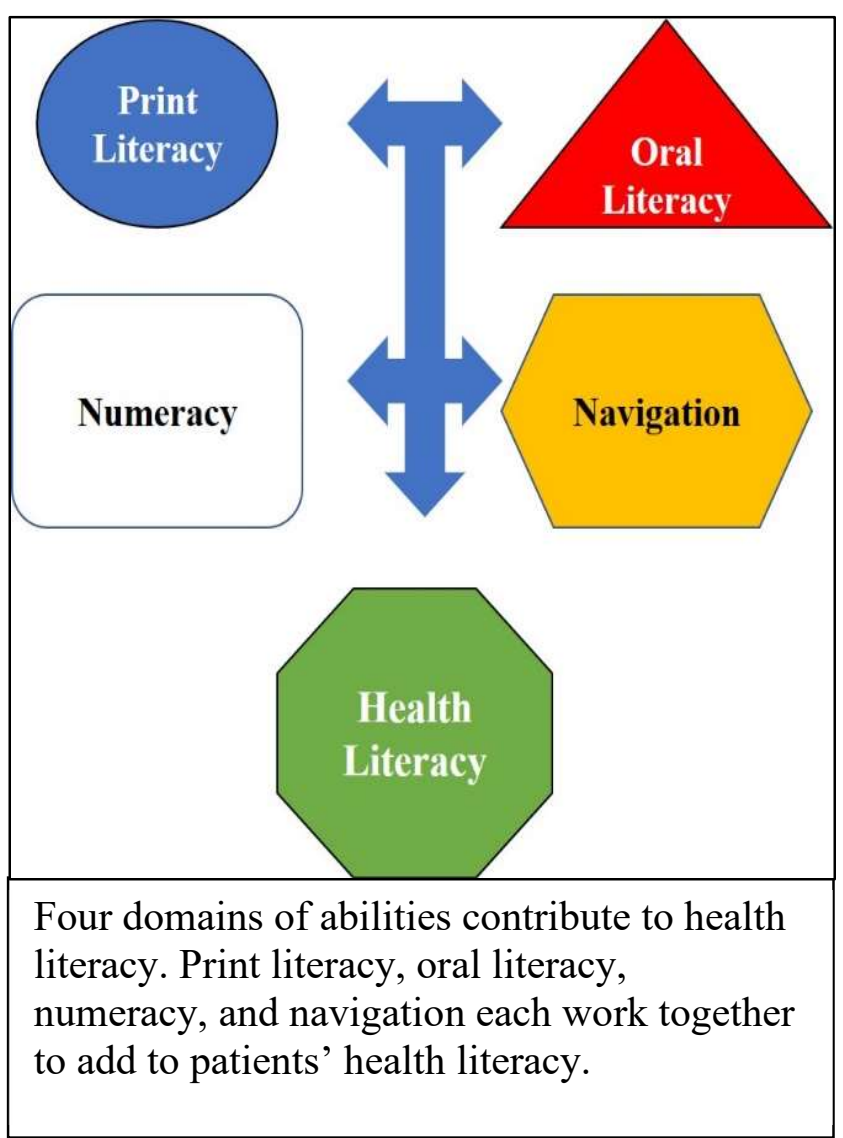

literacy was analyzed. The Short Form of the HLSI has a Cronbach $\alpha$ of 0.70 for internal consistency and a correlation $\rho=0.90$ to the long form of the instrument. The long form of the instrument showed a Cronbach's $\alpha$ of 0.86 demonstrating a good internal consistency. The higher order confirmatory factor analysis model fit well (CFI $=0.95$, $\mathrm{TLI}=0.98$, and Root mean square error of approximation $($ RMSEA $)=0.03)$ and individual items had strong factor loadings. The HLSI also correlates well with the Short Test of Functional Health Literacy in Adults (S-TOFHLA) scale of health literacy (Bann 
et al., 2012), which is considered the gold standard scale for health literacy. A score of 7 out of 10 questions answered correctly is interpreted as having adequate health literacy.

The Berkman Social Network Scale (BSNS) was used in this study to measure social support network (see Appendix D). The BSNS was originally developed in 1979, and has five dichotomous questions, with a no answer being scored as zero (0) and a yes answer being scored as one (1). A higher score demonstrates greater social support network. The original publication of the instrument demonstrated that increased social interactions showed an inverse correlation with mortality (Berkman \& Syme, 1979). Individuals who were the most isolated were more likely to die from their medical conditions that those who had strong social connections (Berkman \& Syme, 1979). The impact of social networks has been measured on treatment resistant HTN as a part of the Jacksonville Heart Study. In that study, patients with stronger social networks demonstrated a $19 \%$ lower prevalence rate of $\operatorname{HTN}(\mathrm{P}=0.001)$ and showed that treatment resistant HTN was progressively lower with each increase in social network (Shallcross et al., 2017). Other studies have reported good validity and reliability results compared to the BSNS, without reporting statistical data (Kawachi et al., 1996; Pantell et al., 2013).

\section{Data Management}

Data was collected utilizing an Acer tablet computer to administer the surveys and at the conclusion the responses were automatically saved into a password protected file within Qualtrics. The laptop was maintained in a secure location throughout data collection. Final data sets were transferred to SPSS for analysis. All procedures for managing data were approved by the University of Missouri's Institutional Review Board. 


\section{Data Analysis}

Descriptive statistics were calculated for all demographic data and survey scores. Percentages were reported for each categorical measure, including self-reported medication adherence. Health literacy was reported as the percent of the sample that had a score indicating adequate health literacy. Spearman correlations were calculated between all variables in the study. Logistic regression was performed to examine the relationships between demographic characteristics and variables of interest to this study. Statistical significance was set at $\mathrm{p}<0.05$.

To address aim one, To explore the relationship between medication adherence, health literacy, and social support network among ED patients who are currently being treated for HTN, relationships between medication adherence, health literacy and social support network scores were examined. Medication adherence was scored as nonadherent if a participant responded to any of the BAASIS questions with an answer other than never. The total score was used for health literacy. Social support network was evaluated as a continuous variable.

To address aim two, To explore the feasibility and acceptability of conducting a cross sectional study in the ED setting among adult patients that presented with an acute health problem, together with a history of HTN, the number of people that were approached about the study, the number that accepted, the number that declined, and the reasons that people declined were examined. By examining the number of potential participants that were approached for the study, compared to the number that met inclusion criteria and the number who were amenable to and completed the study questionnaires, the feasibility and acceptability of performing this type of research was 
assessed. This analysis was conducted in an effort to gain insight into the barriers and facilitators for conducting research focused on chronic health conditions in the ED setting.

\section{Protection of Human Subjects}

This study was approved by the University of Missouri-Columbia, Health Sciences Institutional Review Board (IRB) (Protocol 2016741). Potential participants were approached during their ED visit by the PI. Care was taken throughout the course of the study to ensure that study participation did not interfere with the provision of medical care. The PI informed potential participants that the intent of the research was to better understand how patients take their antihypertensive medicines and to help health care providers take better care of patients with HTN.

Administration of all components of the study took approximately 20 minutes per participant. During the administration of the study instruments, it was necessary to pause the administration for one patient in order to allow for treatments to be performed.

Study participation was voluntary. Interested individuals were informed that they could withdraw from the study at any time without consequences and that nonparticipation would not impact their ED care. Participants were informed that their responses to the surveys would be analyzed collectively and that no individual data would be identifiable. Each data point of the study was isolated within the testing tool so that responses to questions could be assessed together. Participants were informed of the potential for publication. 


\section{Data Safety and Monitoring}

To assure data safety, data was entered using a laptop that was password protected and was secured at any time that it was not in use. No participant information will be shared with anyone who is not a part of the study. All study personnel completed CITI training.

\section{Inclusion of Women and Minorities}

Convenience sampling was used with the pre-defined inclusion and exclusion criteria, rather than on any arbitrary or prejudicial basis. No attempts were made to select individuals of a specific gender or race/ethnicity when assessing for inclusion in the study. The study was conducted in a community that is known to have more males than females with HTN, and there are more non-Hispanic Blacks with HTN than any other race. Though this demographic has the potential to increase the proportion of non-Hispanic Black males in comparison to other demographic groups, efforts were not made to selectively recruit members from any racial or gender group for the study, rather all potential participants were evaluated for inclusion and approached for informed consent.

\section{Inclusion of Children}

Children were expressly excluded from this study. 


\section{CHAPTER FOUR: RESULTS}

This study had two aims: (1) To examine the relationship between medication adherence, health literacy, and social support network among patients in the ED setting that presented with an acute health problem, together with a history of HTN; (2) to explore the feasibility and acceptability of conducting a cross sectional study in the ED setting with patients that present with an acute health problem, together with a history of HTN.

\section{Participant Characteristics}

Data Collection was completed between August 18, 2019 and March 8, 2020. Participants $(n=50)$ were predominantly Caucasian $(60 \%)$, male $(56 \%)$, and between the ages of 41-60 (46\%) [see table 1]. Most participants in this study had completed high school (90\%) and half were married (46\%) or partnered (4\%). Most participants reported having full time employment (56\%), however, only $32 \%$ of participants reported having health insurance through their employer. Regarding last primary health care provider (PCP) visit, $32 \%$ of participants reported seeing their PCP within the last month and $26 \%$ reported they had not seen their PCP within the last year, the remaining participants had seen their PCP between one month and one year prior to completing the survey. All participants that began the survey completed the participant response sections. In one case, a staff nurse from the department took the tablet from the participant following their completion and shut the tablet which closed the survey prior to the researcher being able to enter the chief complaint and BP.

The reason for ED visit was recorded in 49 of the 50 responses, participants presented with varied reasons for their visit. Twenty-eight unique reasons for visiting the 
ED were recorded. The reasons for ED visit included abdominal pain, chest pain, and headache with five (5) visits each. Other reasons for ED visits were extremity pain and breathing difficulties with four (4) visits each. There was only one visit that specifically listed HTN as the reason for visiting the ED.

Upon presentation to the ED, participants' BP readings were highly varied. BPs were recorded for 49 of the 50 responses. Of the participants' initial BPs, only four (4) participants had normal BP readings $(<120 /<80 \mathrm{mmHg})$ according to the standards of the AHA (Wald et al., 2018). An additional four (4) participants had elevated blood pressure, 27 participants had either grade 1 or $2 \mathrm{HTN}$, and 14 participants were in a hypertensive crisis with a range of 180-256/80-142 $\mathrm{mmHg}$.

\section{Relationship between Medication Adherence and Demographic/Health Variables}

Medication adherence was assessed using the BAASIS. The majority of participants (64\%) self-reported non-adherence to their anti-hypertensive medications, while just over a third (36\%) indicated that they were adherent to their anti-hypertensive medications [Table 2]. Correlations between medication adherence and demographic variables were also examined. The variable with the strongest correlation to medication adherence was last primary care provider (PCP) visit [Table 4]. Length of time between last PCP visit and medication adherence had a negative, moderate correlation of -..473 $(\mathrm{p}<0.01)$. This correlation demonstrates that the closer to the participant's last visit to their PCP was, the more likely they were to be adherent to their prescribed medication. Medication adherence was also moderately correlated to adequate health literacy $(0.459$ $\mathrm{p}<0.01)$. Higher level of education was correlated with increased medication adherence, $\mathrm{p}<0.01$ (0.386). Social support network and insurance status had moderately weak 
positive correlations to medication adherence with $\mathrm{p}<0.05$ ( 0.351 and 0.298 respectively). There were no significant correlations found between age, gender, race, marital status, and employment status with regard to medication adherence.

\section{Relationship between Health Literacy and Demographic/Health Variables}

The HLSI-SF was utilized to assess health literacy. Of the 50 participants, only $42 \%$ were found to possess adequate health literacy [Table 2]. Each variable in comparison to health literacy showed very weak, or weak correlations. The strongest correlation with health literacy was insurance status $(0.473,(p<.01))$ [Table 5]. Education also had a significant, but moderately weak, correlation to health literacy at 0.369 $(\mathrm{p}<0.01)$. Primary care visits and social network had less significance but still showed moderately weak correlations to health literacy. Last PCP visit had a negative correlation of $-0.330(p<0.05)$ which implies that the shorter distance between their last PCP visit and their ED visit the more likely they were to have adequate health literacy. Social support network correlated with health literacy at a value of $0.393(p<0.05)$ demonstrating that as individuals increased the size of their support network, they increased the likelihood of having adequate health literacy. Age, gender, race, marital status, and employment were not statistically significant with regard to adequate health literacy.

\section{Relationship between Social Support Network and Demographic/Health Variables}

The BSNS as adapted by Shallcross (2017) was utilized in this study to assess social support network. While responses were recorded for every level of social support network integration, more individuals indicated the most integrated level of social 
support network than any other response [Table 2]. The strongest correlation with social network is the timing of the last visit to the participant's PCP [Table 6]. The correlation between social support network and the timing of the last primary care visit is the only relationship found to have a moderate correlation. The correlation between social support network and primary care visit is $-0.573(\mathrm{p}=0.000)$, again showing that those participants with shorter times since last PCP visit were more likely to be well integrated into their social network. Education and insurance status are also both significantly, though moderately, correlated with higher social network scores $(0.361(\mathrm{p}<.01)$ and 0.338 $(\mathrm{p}<.05)$ respectively). There were no significant correlations between social support network and age, gender, race, marital status, or employment status.

\section{Relationship between Medication Adherence, Health Literacy and Social Support Network}

Significant correlations were found between medication adherence, health literacy, and social support network [Table 3]. The association of each variable showed, at best, moderate correlations. Logistic regression was used to examine the relationship between medication adherence, health literacy and social support network and to calculate the odds of medication adherence increasing as levels of health literacy and social support network increased. Adjustments needed to be made to the regression model, due to the finding that all participants who did not complete HS were nonadherent and all participants who did not have insurance were non-adherent. This created an estimation problem due to complete separation of data points when included in the logistic regression model therefore level of education and insurance status were omitted 
from the fit model. Adequate health literacy resulted in a $13.71(95 \% \mathrm{CI}=[2.18: 86.19]$, $\mathrm{p}=0.005$ ) increase in the likelihood that a participant would be adherent to his/her HTN medications. Marital status was found to significantly increase the likelihood of being adherent to one's medications. Being married or partnered resulted in a $7.44(95 \%$ $\mathrm{CI}=[1.36: 40.72], \mathrm{p}<0.05)$ increased odds of being adherent compared to those that are single, divorced or widowed. Lastly, being employed increased chances of being adherent by a factor of $7.07(95 \% \mathrm{CI}=[1.09: 45.78], \mathrm{p}<0.05)$ compared to those that were unemployed or retired. In contrast, increasing integration into the social support network was not significant $1.29(95 \% \mathrm{CI}=[0.41: 4.1], \mathrm{p}=0.67)$ with regard to the likelihood that a participant would be adherent to his/her HTN medications.

\section{Feasibility and Acceptability}

The second aim of the study was to evaluate the feasibility and acceptability of conducting a cross-sectional research study in a high-volume ED. During the nearly sixmonth course of the study, 600 participants were screened for inclusion in the study. Of those screened, 140 met initial inclusion criteria and were invited to participate. Of the 140 which met initial inclusion criteria, there were 127 who made all their own healthcare decisions and prepared their own medications for administration and adherence. Ultimately, 50 adults participated in the study, a response rate of $39.4 \%$. There were a variety of reasons given for non-participation. Of note, the most common reasons given for non-participation was "forgetting glasses at home". Also mentioned were "being in too much pain", and "not wanting to be involved in research". 
Table 1: Participant $(\mathrm{n}=50)$ Characteristics

\begin{tabular}{|c|c|c|}
\hline Characteristic & $\begin{array}{c}\text { Frequency } \\
\text { (n) }\end{array}$ & $\begin{array}{c}\text { Percent } \\
(\%)\end{array}$ \\
\hline \multicolumn{3}{|l|}{ Gender } \\
\hline Male & 28 & 56.0 \\
\hline Female & 22 & 44.0 \\
\hline \multicolumn{3}{|l|}{ Age } \\
\hline 18-40 Years Old & 13 & 26.0 \\
\hline 41-60 Years Old & 23 & 46.0 \\
\hline Over 60 Years Old & 14 & 28.0 \\
\hline \multicolumn{3}{|l|}{ Race } \\
\hline Caucasian / White & 30 & 60.0 \\
\hline African American / Black & 15 & 30.0 \\
\hline Hispanic & 3 & 6.0 \\
\hline Pacific Islander / Asian & 2 & 4.0 \\
\hline \multicolumn{3}{|l|}{ Education } \\
\hline Less than High School & 5 & 10.0 \\
\hline High School Graduate & 21 & 42.0 \\
\hline Some College & 7 & 14.0 \\
\hline 2 - Year Degree & 4 & 8.0 \\
\hline 4 - Year Degree & 9 & 18.0 \\
\hline Professional Degree & 3 & 6.0 \\
\hline Doctorate & 1 & 2.0 \\
\hline \multicolumn{3}{|l|}{ Marital Status } \\
\hline Single & 11 & 22.0 \\
\hline Partnered & 2 & 4.0 \\
\hline Married & 23 & 46.0 \\
\hline Divorced & 9 & 18.0 \\
\hline Widowed & 5 & 10.0 \\
\hline
\end{tabular}


Characteristic

Frequency Percent

Employment

(n)

$(\%)$

Full Time Employed

$28 \quad 56.0$

Retired

$13 \quad 26.0$

Part Time Employed

12.0

Unemployed, Not Seeking Employment

Unemployed, Seeking Employment

$5 \quad 10.0$

Student with Additional Employment

24.0

12.0

Student without Additional Employment

Insurance Status

No Insurance, Self-Pay

0

0.0

Medicaid

$10 \quad 20.0$

Medicare

12

12

24.0

Employer Based Insurance

$10-20.0$

On Parents' Insurance

$16 \quad 32.0$

Affordable Care Act Marketplace Acquired

$1 \quad 2.0$

Insurance

Last Primary Care Provider Visit

Within the Last Month

$1 \quad 2.0$

1-3 Months

16

32.0

3-6 Months

$8 \quad 16.0$

6 Months - 1 Year

$3 \quad 6.0$

More than 1 Year Ago

$10 \quad 20.0$

$13 \quad 26.0$ 
Table 2. Medication Adherence, Health Literacy, Social Support Network Scores Survey Scores Frequency (n) Percent (\%)

Adherence to Medications (BAASIS)

No

64.0

Yes

Adequate Health Literacy (HLSI)

No

Yes

Social Support Network (BSNS)

Number of Unique/ Active

Sources of Social Contacts Most Isolated ( 0 or 1 ) Moderately Isolated (2or 3) 3

6.0

Moderately Integrated (4) Most Integrated (5) 13

26.0

30.0

19

38.0 
Table 3: Relationship Between Medication Adherence, Health Literacy, and

\begin{tabular}{l|c|c} 
& \multicolumn{2}{c}{ Social Support Network. } \\
& Correlation $(\rho)$ & p-value \\
\hline $\begin{array}{l}\text { Medication Adherence * } \\
\text { Health Literacy }\end{array}$ & 0.459 & 0.001 \\
\hline $\begin{array}{l}\text { Medication Adherence * } \\
\text { Social Support Network }\end{array}$ & 0.351 & 0.012 \\
\hline $\begin{array}{l}\text { Health Literacy * Social } \\
\text { Support Network }\end{array}$ & 0.393 & 0.05
\end{tabular}

Table 4: Relationship between Medication Adherence and demographic variables

Primary Care Visit

Pearson

Correlation p-value

Education

$-0.473$

0.001

Insurance Status

0.386

0.006

Age

0.298

0.036

Gender

0.206

0.150

Race

$-0.091$

0.531

Marital Status

0.206

0.077

Employment

0.027

0.851

$-0.048$

0.740 
Table 5: Relationship between Health Literacy and demographic variables

$\begin{array}{llr} & \text { Pearson } & \\ & \text { Correlation } & \text { p-value } \\ \text { Primary Care Visit } & -0.330 & 0.019 \\ \text { Education } & 0.369 & 0.008 \\ \text { Insurance Status } & 0.473 & 0.001 \\ \text { Age } & -0.133 & 0.355 \\ \text { Gender } & -0.144 & 0.320 \\ \text { Race } & -0.174 & 0.228 \\ \text { Marital Status } & -0.063 & 0.663 \\ \text { Employment } & -0.192 & 0.182\end{array}$

Table 6. Relationship Between Social Support Network, and Demographic Variables

Primary Care Visit

Pearson

Education

Correlation p-value

Insurance Status

$-0.573$

0.000

0.361

0.010

Age

0.338

0.016

$0.088 \quad 0.542$

Gender

$-0.212$

0.140

Race

$-0.277$

0.051

Marital Status

0.062

0.670

Employment

$-0.223$

0.120 
Table 7. Logistic Regression of demographic and variables of interest to Medication Adherence, following reduction in model of factors that did not statistically contribute to medication adherence

$$
95 \% \mathrm{CI}
$$

EXP(B) p-value LOWER UPPER

\begin{tabular}{lcc|c|c} 
Marital Status & 7.44 & .02 & 2.18 & 86.19 \\
\hline Employment & 7.07 & 0.04 & 1.36 & 40.72 \\
\hline Health Literacy & 13.71 & 0.005 & 2.18 & 86.19 \\
\hline Social Support & & & & \\
Network & 1.29 & 0.67 & 0.41 & 4.1 \\
Integration & & & & \\
\hline
\end{tabular}




\section{CHAPTER 5: DISCUSSION}

This study used a convenience sample of hypertensive patients that visited one ED located in mid-Missouri, which is not representative to the hypertensive population at large within the state of Missouri. The study sample had a high percentage of Caucasian participants who were 41-60 years of age, whereas the state population as a whole reflects that demographic group with the highest incidence of HTN are greater than 65 years old and African American (Li \& Yun, 2013). The differences in age and race for the study, versus the population, are likely due to the inclusion/ exclusion criteria of the study. The requirement that study participants must make their own medical decisions and manage their own medications increases the likelihood that an older adult would not meet inclusion criteria for this study. In fact, only one participant over the age of 80 met all criteria to be included in the study. Missouri demographics also show a significantly greater number of women, than men, reporting to the ED for HTN related visits (Li \& Yun, 2013), whereas more men were evaluated as a part of the current study. Differences between the population of Missouri at large and the study sample may also be a factor of convenience sampling and location. It should also be noted that the study site was not located in either of the two regions of the state with higher population density which had the highest absolute numbers, or the most rural areas of the state which had the most per capita.

When examining the relationship between medication adherence, health literacy, and social support network among ED patients who participated in this study, positive correlations were found between medication adherence and both health literacy and social support network. Findings from the current study suggest that adequate health 
literacy improves medication adherence. This finding is similar to findings from previous studies, which have shown that health literacy is a stronger predictor of medication adherence than social support network. Of note is the finding that medication adherence was higher among participants with a recent visit to a primary care provider. The positive relationship between medication adherence and recent primary care visit was not a surprising factor given the evidence that chronic medical conditions are well managed in the primary care setting (Elwenspoek et al., 2019).

Findings from this study indicate that it is feasible and acceptable to conduct research in the ED setting that focuses on a chronic health condition (i.e. HTN). However, it is notable that despite the fast-paced, high patient volume ED setting, it took approximately six (6) months to enroll 50 participants. One reason for the low uptake in study participation could be that there were multiple ongoing research studies in the same setting. Although, the other studies were focused on low frequency, highly critical conditions and did not really compete for the same participant pool.

It is of importance to consider the fact that the current study was conducted without providing participants with an incentive for participation. Many studies that examine the effectiveness and response rates to research studies offer some level of incentive. These incentives can be monetary (cash or gift cards), or lottery based and prepaid or post-paid (Saleh \& Bista, 2017). Pre-paid incentives have shown a positive impact on participation (Saleh \& Bista, 2017). As a similar length, non-incentive survey, the Press-Gainey Patient Satisfaction Survey has an average response rate of only 11\% (Tyser et al., 2016). 
A variety reasons were given for not participating in the current study including "I just don't feel like it", “I'm not a test subject", and "get out of here until you do something for my pain". The most common reason was that they "forgot their glasses". A well-established trend in studies that focus on health literacy has been that individuals with low health literacy state that they "forgot their glasses" in order to hide low health literacy (Jahagirdar et al., 2012; Neter \& Brainin, 2019). This phenomenon was likely seen in the current study as well, as 20 potential participants stated that they could not participate due to not having their glasses. Despite reasons given for not participating in the study, the response rate was acceptable and falls in the middle of reported ranges.

Since the inception of this study, new articles have been published that examined the role that uncontrolled BP among ED patients plays in morbidity and mortality (Astarita et al., 2020; Oras et al., 2020; Saladini et al., 2020; Tocci et al., 2020). Each of these studies examined the roles that hypertensive emergencies, and urgencies play in morbidity and mortality as well as suggesting changes in treatments to improve outcomes. Two studies examined the role of non-adherence in admission to the ED with hypertensive crises (Overgaauw et al., 2019; Wallbach et al., 2019). These two studies used biochemical assay for the HTN medications that patients were supposed to be taking once they arrived in an ED with hypertensive crisis (Overgaauw et al., 2019; Wallbach et al., 2019).

Lastly, the feasibility of conducting a HTN study in the ED was evaluated in a study examining home BP measurements (Meuer et al., 2019) This study enrolled ED patients in the study, provided them with a BP cuff and then sent text messages so that patients would take BP readings at home. This study, while conducted with ED patients, 
required home interaction, and did not collect the data during their ED visit. The study received an approximate $70 \%$ response rate but did not produce a statistically significant reduction in SBP among participants (Meurer et al., 2019).

Despite the recently published articles, no study was found that specifically examined the characteristics of patients in the ED setting for chief complaint, or medication adherence, health literacy, social support network levels. Assessing these baseline measurements for this population could aid in designing interventions and treatment recommendations to improve the health outcomes and quality of life for this vulnerable population. Research in the ED is difficult to undertake due to many factors, among them are: inadequate time, inadequate training, and often inadequate funding (Good \& Driscoll, 2002). These factors can be overcome within a facility which has a strong focus on research and a researcher that is devoted to engaging the ED patient population (Good \& Driscoll, 2002; Mutter \& Clancy, 2014; Smith \& Morley, 2015).

All data in this study were collected by one person, the PI. During the PI's data collection period nearly $25 \%$ of all patients that were seen in the ED met inclusion criteria. This number could have been even higher if patients with time critical diagnoses could have been considered for inclusion, as HTN is the leading cause of both cerebrovascular and cardiovascular events (Mozaffarian et al., 2015). Additionally, had there been a larger group of study personnel doing recruitment, more patients would have been screened for possible participation. Findings from this study suggests that it is both feasible and acceptable to conduct research that focuses on chronic health conditions in a high performing ED setting. However, recruitment procedures could be improved by 
streamlining the screening process and by having more study personnel available to enroll participants.

\section{Implications for Future Research}

This study while adding to the extant research on medication adherence, health literacy and social support network also provides future research opportunities. One opportunity is to increase the sample size through utilization of additional researchers, research locations, and increased hours of data collection. Additionally, expanding the inclusion criteria to include patients being seen for time critical diagnoses may increase the potential participants as long as survey administration does not impact patient care. This addition has the potential to alter results as patients who have low medication adherence and HTN are more likely to suffer from cardiac and neurovascular events (CDC,2016).

An additional opportunity is to better explore the role of primary care in the healthcare of ED patients. This study found that $46 \%$ of participants had not had a primary care visit for over 6 months, what is not known about those participants is whether they had a PCP, whether their PCP had instructed them that they did not need to visit more than once a year, or any other contributing factor that may have caused the appointment gap. One potential contributing factor could be that the PCP felt that the participant's HTN was under control and they did not need to be attending clinic appointments as frequently, however, in this study only four participants had BP values that indicated control of their HTN.

A final opportunity to address a potential limiting factor of the study is the timing of the BP measurement. Due to the nature of emergency care, patients may initially have 
elevated BP measurements compared to their normal baseline. The additional stressors of the need to be in an ED, white coat syndrome, and their physical ailment may all play a part in elevating their BP on initial screening. Future studies should consider the timing of recording a $\mathrm{BP}$ on participants and potentially examine final $\mathrm{BP}$ in the ED rather than first. Examining the final BP may create additional sources of error however as the survey will likely be completed long before disposition and either discharge from the ED or admission to the hospital, and keeping track of administration of a deidentified survey to connect it with the BP measurement of the ED patient could be difficult. The difficulty in getting an accurate discharge BP has several factors in it. Some nurses only record vital signs every hour, others every $10-15$ minutes. There is a possibility that a patient may not have had a BP taken for up to an hour prior to it being collected if it is taken at discharge. Additionally, an individual that completes the deidentified survey four hours prior to discharge, or perhaps does not even discharge prior to study staff going home for the night would be a highly difficult data point to acquire without enhanced access to the medical record that would make a study non-exempt from the IRB.

\section{Conclusion}

The ever-changing landscape of healthcare in the United States has resulted in a trend where Americans use the ED and urgent care setting for primary care and to meet their healthcare needs. Chronic health conditions require ongoing management that is challenging to provide in an ED setting, which is designed to address acute and critical health care problems. There is a need for the nation's ED health care providers and for health care systems to re-examine ED health care delivery and develop effective 
strategies that can help people who present with untreated and uncontrolled chronic health conditions, such as HTN, to better manage their health.

This study adds to the evidence that it is realistic to undertake research that focuses on enhancing chronic disease outcomes in the ED setting. The demonstrated link in this study, and others, between health literacy and medication adherence cannot be ignored. Novel interventions are needed to assess health literacy in the ED setting. Currently, the typical strategy is to present ED patients with printed materials about chronic health conditions without an assessment of whether the person can read or understand such materials. Moreover, ED patients are often told to follow-up with their PCP. However, this study, and others, have shown that many ED patients do not visit their PCP often for health care. Lastly the research community needs to recognize that there are untapped opportunities for conducting research that focuses on chronic health conditions in the ED setting. 


\section{Appendix A}

\section{Demographic Data Collection}

What gender were you assigned at Birth?

Male

Female

What Race/ Ethnicity do you most identify with?

Caucasian/ White

African American/ Black

Asian/ Pacific Islander

Hispanic

What is the highest level of Education you completed?

Less than High School

High school graduate

Some college

2 year degree

4 year degree

Professional degree

Doctorate

What is your Marital Status?

Single

Married

Partnered

Divorced

Widowed 
Which Age Group are you a part of?

18-40 years old

41-60 years old

61-80 years old

$>80$ years old

What is your current Employment Status?

Full time employed

Part time employed

Student with no additional employment

Student with additional employment

Unemployed, seeking employment

Unemployed, not seeking employment

Retired

What type(s) of medical insurance do you currently possess?

No insurance/ self-pay

On parents' insurance

Self-insured

Employer based insurance

Affordable Care Act Marketplace acquired insurance

Medicaid

Medicare

Tricare

VA Benefits

When was your last visit to your Primary Care Provider?

Within the last month

1-3 months

3-6 months

6 months to 1 year

More than 1 year ago 


\section{Appendix B \\ Basel Assessment of Adherence to Immunosuppressive medications Scale (BAASIS) (De Bleser et al., 2011)}

How often in the last 4 weeks have you missed your medications?

Never

Sometimes

About half the time

Most of the time

Always

How often in the last 4 weeks have you taken your medication more than 2 hours before or 2 hours after the prescribed taking time?

Never

Sometimes

About half the time

Most of the time

Always

How often in the last 4 weeks have you skipped at least two consecutive doses of your medications?

Never

Sometimes

About half the time

Most of the time

Always

How often in the last 4 weeks have you reduced the prescribed amount of your medication in order to make it last longer?

Never

Sometimes

About half the time

Most of the time

Always 
Health Literacy Skills Instrument - Short Form (HLSI-SF) (Bann et al., 2012)

*Correct Answers are marked in bold*

\section{Cholesterol: Know What Your Level Means}

- Cholesterol: What Your Level Means

- What is cholesterol?

- Cholesterol is a waxy substance the body uses to protect nerves, make cell tissues and produce certain hormones.

- Are there different types of cholesterol?

- Yes. Cholesterol travels through the blood in different types of packages, called lipoproteins.

- Low-density lipoproteins (LDL) deliver cholesterol to the body. High-density lipoproteins (HDL) remove cholesterol from the bloodstream.
- Total cholesterol level

- Less than 200 is best.

- 200 to 239 is borderline high.

- 240 or more means a person is at increased risk for heart disease.

- LDL cholesterol levels

- Below 100 is ideal for people who have a higher risk of heart disease.

- 100 to 129 is near optimal.

- 130 to 159 is borderline high.

- 160 or more means a person is at a higher risk for heart disease.

- HDL cholesterol levels

- Less than 40 means a person is at higher risk for heart disease.

- 60 or higher greatly reduces a person's risk of heart disease

Which set of low density lipoprotein (LDL) and high density lipoprotein (HDL) levels is best?

LDL of 134 and HDL of 61

LDL of 98 and HDL of 82

LDL of 140 and HDL of 50

LDL of 165 and HDL of 80

Please listen to the audio recording, then answer the question.

If a person was worried about his cough, what number should he press?
1
2
4

Call 911

Not Sure 


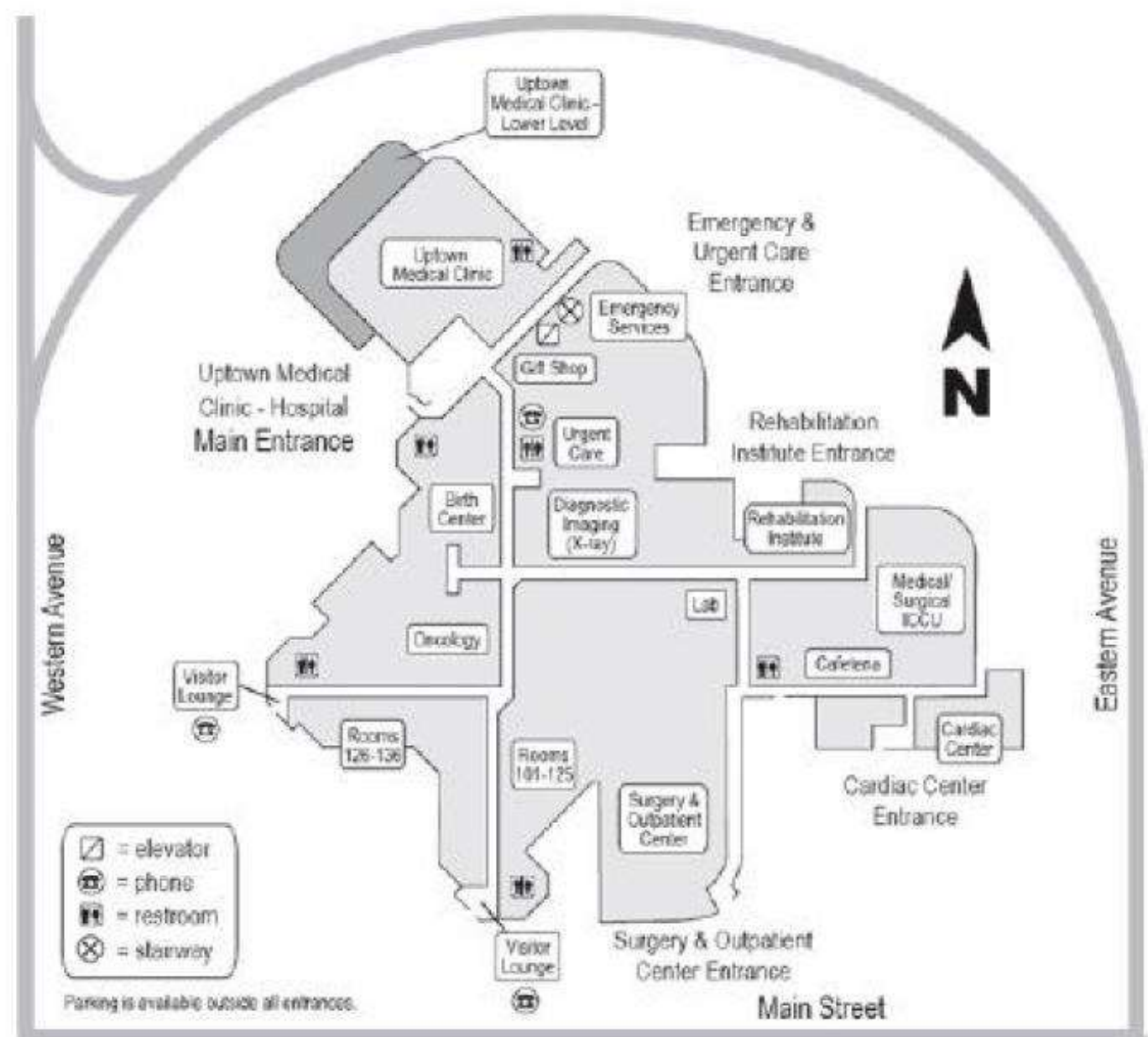

Based on the picture above, which of the following entrances is closest to the elevator?

There is no elevator

Surgery \& Outpatient Center Entrance

Rehabilitation Institute Entrance

Main Entrance

I Don't Know 


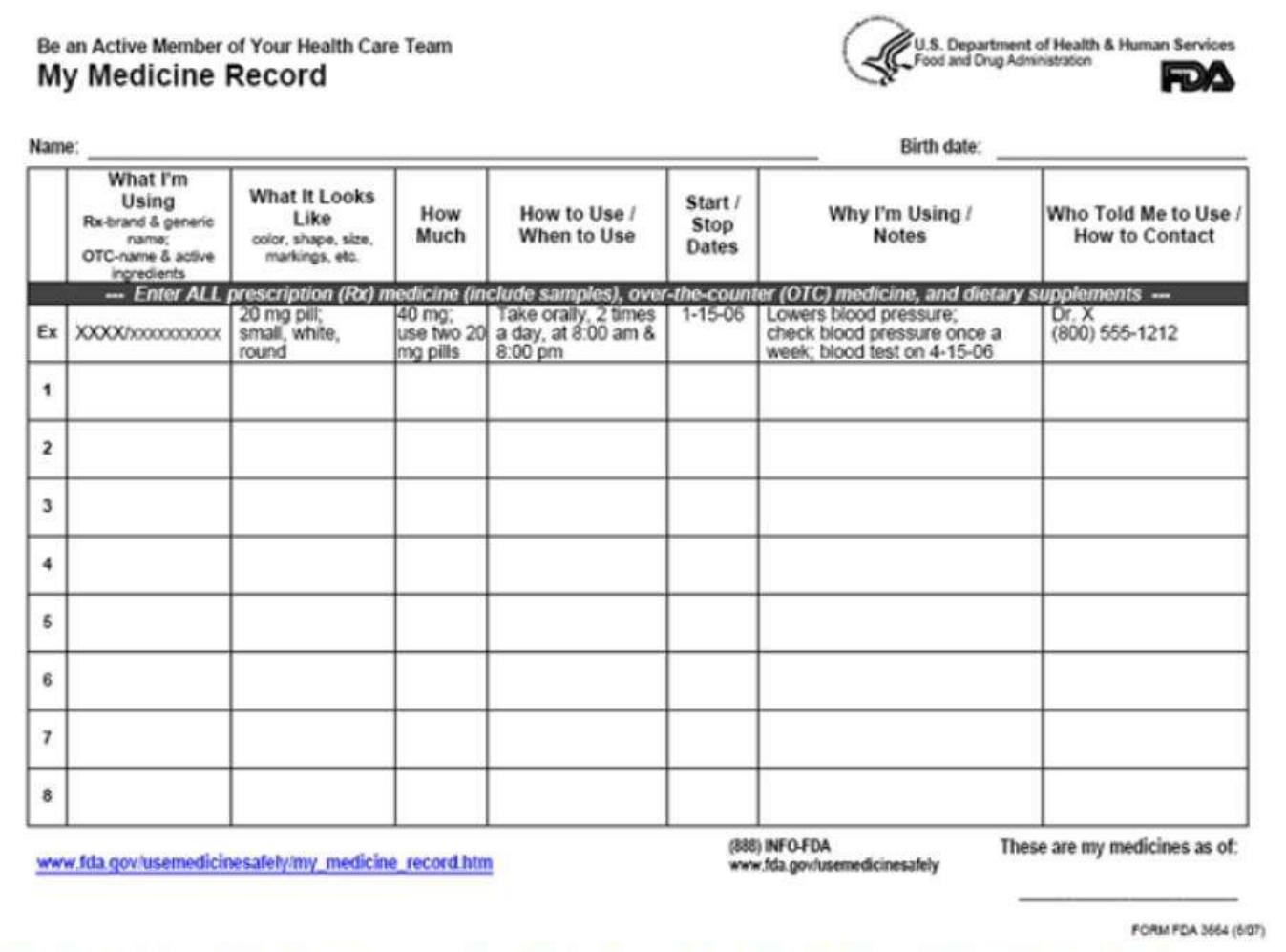

Please answer the following questions based on the information in the chart.

In the example listed in the first row of the table, when should the medicine be taken?

Two times a day, anytime between 8 a.m and 8 p.m.

At 8 a.m. or 8 p.m. each day

At 8 a.m. and 8 p.m. each day

I don't know

Please read the question below, then visit the following website to answer the question based on the information in the website.

https://www.cardiosmart.org/healthwise/tx43/94/tx4394

Kate weighs 150 pounds. Which activity would burn the most calories?

Walking at a medium pace for 30 minutes

Raking the lawn for 30 minutes

Bowling for 30 minutes

Don't know 


\section{Signs of a Stroke}

My motber is alive today because a police officer knew the signs of a stroke. You can save a life, too, if you learn these signs.

Mom was on her way to the dentist when a police officer noticed she was driving strangely and started to follow her. She pulled over on the highway. When the officer approached her, she told him she had a blinding headache. But she said that she had to get to her dentist appointment on time.

The officer also noticed that mom just wasn't acting right. Some of her speech was confused. And she was a little dizzy.

Mom said she felt fine, but that didn't stop the officer. He quickly called 911. That call saved my mother's life.

Knowing the signs of a stroke could help you save a life, too. Remember, some people have all of these signs, but my mom only had a few.

If you or someone else has even a few of these signs, get help fast!

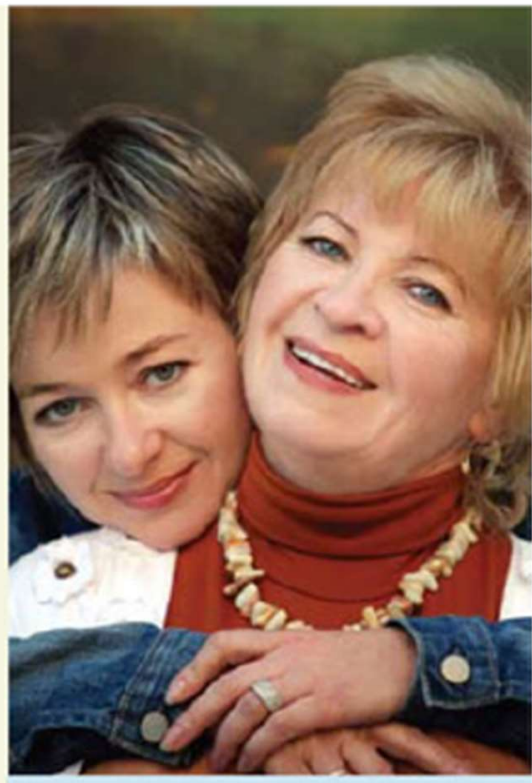

\section{Five Signs of a Stroke}

- Sudden numbness or weakness of the face, arm or leg, especially on one side of the body

- Sudden confusion, trouble speaking or understanding

- Sudden trouble seeing in one or both eyes

- Sudden trouble walking, dizziness, or loss of balance

- Sudden, severe headache

American Strolve Prewention

Please answer the following question based on the information in the flyer. Which of the following is NOT a sign of a stroke?

Shaking chills

Blurred vision

Bad headache

Numbness on one side

Don't know 


\title{
Portion Control for Weight Loss
}

Expanding portions

\begin{abstract}
Are you eating a variety of healthy foods, exercising and still struggling with your weight? Some people may need to pay closer attention to portion control - managing the amount of food that they eat - as their total calorie intake determines their weight.

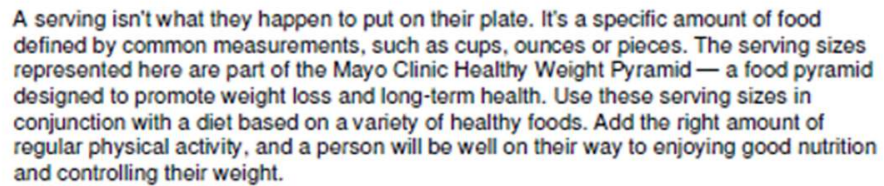

Until they're comfortable judging serving sizes, you may need to use measuring cups and spoons. A half a cup of cooked carrots, for example, equals one serving. Here are the recommended serving sizes for other vegetables:

Food $\begin{aligned} & \text { Serving } \\ & \text { size }\end{aligned}$
$\begin{aligned} & \text { Raw leafy }=2 \text { cups } \\ & \text { vegetables }\end{aligned}$
Raw = 1 cup
vegetables,
chopped
$\begin{aligned} & \text { Chopped, = } \\ & \text { cooked or } \\ & \text { canned } \\ & \text { vegetables }\end{aligned}$

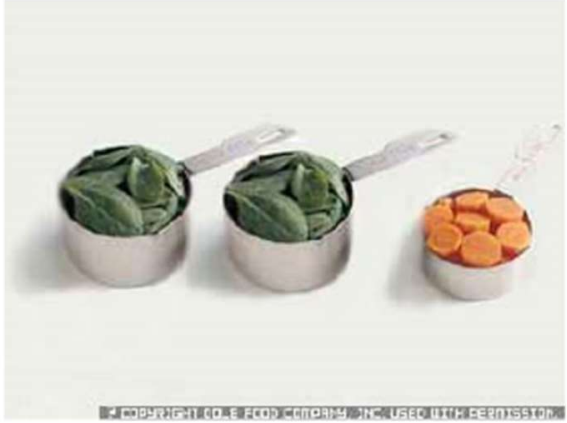

Meat and beans

Familiar objects can help a person picture proper portions for meat, poultry, fish and beans. For example, a 3-ounce serving of fish is about the size of a deck of cards. Here are the serving sizes for meat and meat substitutes:

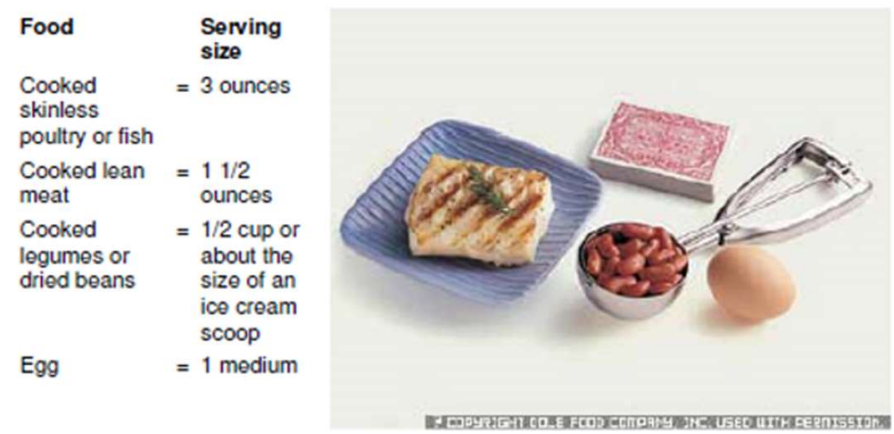

Used with permission from Mayo foundation for Medical Education and Research. "Mayo," "Mayo Clinic," "Mayoclinic.com," "Mayo Clinic Health Information," and the triple-shield Mayo logo are trademarks of MFMER. All Rights Reserved.

Please answer the following questions based on the information in the text and charts. A person is cooking dinner for himself and he wants to include one serving from the meat and beans group. What should he choose?

\section{$11 / 2$ ounces of cooked lean beef}

\section{$11 / 2$ ounces of cooked fish}

3 boiled eggs

1 cup of cooked kidney beans

Don't know 
https://www.mayoclinic.org/healthy-lifestyle/fitness/multimedia/lunge/vid-20084662

Please answer the following question based on the information in the video clip.

What parts of the body do lunge exercises work?

Arms and Shoulders

Back and Abdomen

Legs and Buttock

Don't Know 


\begin{tabular}{|c|c|c|c|}
\hline \multirow{4}{*}{$\begin{array}{l}\text { Nutrition Facts } \\
\text { Serving Size } 140 \text { grams ( } 140 \mathrm{~g}) \\
\text { Servings Per Container } 1\end{array}$} & \multicolumn{3}{|c|}{$\begin{array}{l}\text { "Percent Daily Values are based on a } 2.000 \text { calorie } \\
\text { ciet Your daily values may be higher or lower } \\
\text { cepending on your calorie needs: }\end{array}$} \\
\hline & Celories: & \multirow{5}{*}{$\begin{array}{l}2,000 \\
65 \mathrm{~g} \\
20 \mathrm{~g} \\
300 \mathrm{mg} \\
2,400 \mathrm{mg} \\
300 \mathrm{~g} \\
25 \mathrm{~g} \\
\end{array}$} & \multirow{5}{*}{$\begin{array}{l}2,500 \\
80 \mathrm{~g} \\
25 \mathrm{~g} \\
300 \mathrm{mg} \\
2,400 \mathrm{mg} \\
375 \mathrm{~g} \\
30 \mathrm{~g} \\
\end{array}$} \\
\hline & \multirow{4}{*}{$\begin{array}{ll}\text { Tetal Fat } & \text { Less than } \\
\text { Saturated Fat } & \text { Less than } \\
\text { Cholesterol } & \text { Less than } \\
\text { Sodium } & \text { Less then } \\
\text { Total Carbohycrate } \\
\text { Dietary Fiber }\end{array}$} & & \\
\hline & & & \\
\hline Amount Per Sorving & & & \\
\hline Calories from Fat 70 & & & \\
\hline \% Daily Value & & & \\
\hline Total Fat $7 \mathrm{~g}$ & & & \\
\hline Saturated Fat $2.5 \mathrm{~g}$ & & & \\
\hline Trans Fat $\mathrm{Og}$ & & & \\
\hline Cholesterol $25 \mathrm{mg}$ & & & \\
\hline Sodium $300 \mathrm{mg}$ & & & \\
\hline Total Carbohydrate $9 \mathrm{~g}$ & & & \\
\hline Dietary Fiber $2 \mathrm{~g}$ & & & \\
\hline Sugars $3 g$ & & & \\
\hline Protein \&g & & & \\
\hline - Vitamin C $20 \%$ & & & \\
\hline - Iron $10 \%$ & & & \\
\hline
\end{tabular}

Ingredients: Tomaloes; Chicken; Mushrooms; White Wine; Celery; Onions; Oreen Bell Pepper, Flour; Butler; Olve Oi; Salt: Black Pepper.

Sherri Pinero, RD, www.recipeanalysis.com

Please answer the following question based on the information in the label.

If a person is on a 2,500 calorie diet, what percent of the daily value of saturated fat would he get from one serving?

\section{0 percent}

11 percent

12 percent

13 percent

Not Sure 


\section{Number of Men Out of 100 Who Die from Prostrate Cancer Versus Other Diseases}

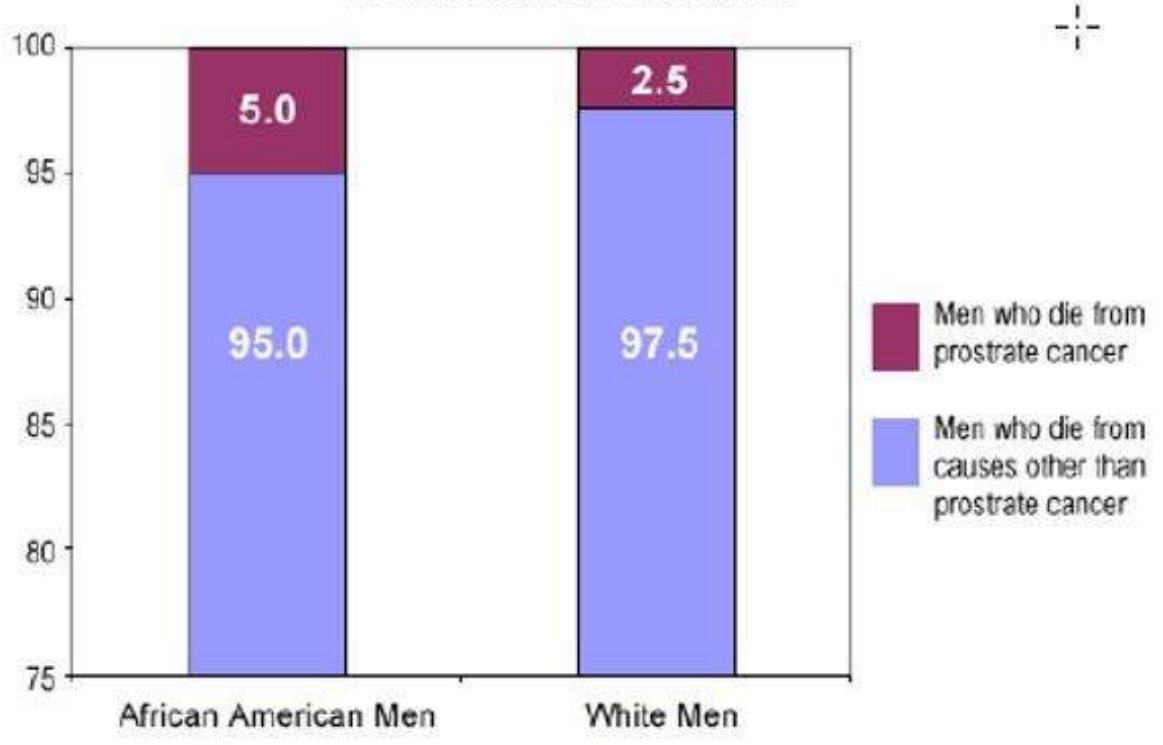

Please answer the following question based on the information in the chart.

More men die from prostate cancer than from other causes. Based on the chart above, would you say this is true, false, or are you not sure?

True

False

Not Sure 


\section{Appendix D}

\section{Berkman Social Network Scale (BSNS) (Berkman \& Syme, 1979; Shallcross et}

\section{al., 2017)}

Are you married, or do you live with someone in a spouse role within your life?

Yes

No

Do you have any close friends, people that you feel at ease with, that you can talk to about private matters?

Yes

No

Do you have any close relatives, family members that you feel at ease with, that you can talk to about private matters?

Yes

No

Do you participate in any groups, such as senior center, social, work group, religiousconnected group, self-help group, or charity, public service, or community group?

Yes

No

Do you have contact with at least one close friend or family member at least once a month?

Yes

No 


\section{Appendix E}

\section{IRB Approval}

Auguas 23, 2019

Principal lnvestigatar: Benjarnin L. Coe

Department: Fmergency Suite

Your IRB Application to project entitled Health Literacy and Medication Adherence in the Hypertensive Bmergency Department Patient was reviewed and approved by the MU Instihutional Review Boand according to the terms and conditions described below:

$\begin{array}{ll}\text { IRB Project Number } & 2016741 \\ \text { IRB Review Number } & 252402 \\ \text { Initial Application Approval Date } & \text { August 23, 2019 } \\ \text { IRB Expiration Dute } & \text { August 23, 2020 } \\ \text { Level of Review } & \text { Exempt } \\ \text { Project Status } & \text { Active- Bxerapt } \\ \text { Bxempt Categories (Revised Common } & \text { 4S CFR 46.104d(2) } \\ \text { Rule) } & \text { Minimal Risk } \\ \text { Risk Level } & \end{array}$

The principal investigator (PI) is responsible for all aspects and condact of this study. The PI must comply with the following conditions of the approval:

1. No subjects may be involved in any study procedure prior to the IRB approval date ar after the expiration date.

2 All changes must be IRB approved prior to implementation utilizing the Exempt Amendment Form.

3. The Annual Exempt Form must be submitted to the IRB for review and appirconl at least 30 days prior to the project expiration date to keep the study active or to clnese it.

4. Maintmin all research records for a period of seven years from the project completion date.

If you have any questions or concerns, please contact the MU IRB Office at $573-8823181$ or emai to muresearchirb fomissouri.edu.

Thamk you,

MU Institutional Review Board 


\section{BIBLIOGRAPHY}

Adisa, R., Olajide, O. O., \& Fakeye, T. O. (2017). Social support, treatment adherence and outcome among hypertensive and type 2 diabetes patients in ambulatory care settings in Southwestern Nigeria. Ghana medical journal, 51(2), 64-77.

Aragão, E. I. S., Portugal, F. B., Campos, M. R., Lopes, C. d. S., \& Fortes, S. L. C. L. (2017). Different patterns of social support perceived and their association with physical (hypertension, diabetes) or mental diseases in the context of primary health care. Ciencia \& saude coletiva, 22, 2367-2374.

Arora, S., Burner, E., Terp, S., Nok Lam, C., Nercisian, A., Bhatt, V., \& Menchine, M. (2015). Improving Attendance at Post-Emergency Department Follow-up Via Automated Text Message Appointment Reminders: A Randomized Controlled Trial. Academic Emergency Medicine, 22(1), 31-37.

https://doi.org/10.1111/acem.12503

Arora, S., Peters, A. L., Burner, E., Lam, C. N., \& Menchine, M. (2014). Trial to examine text message-based mHealth in Emergency Department patients with Diabetes (TExT-MED): A randomized controlled trial. Annals of emergency medicine, 63(6), 745-754.e746 741p. https://doi.org/10.1016/j.annemergmed.2013.10.012

Astarita, A., Covella, M., Vallelonga, F., Cesareo, M., Totaro, S., Ventre, L., Aprà, F., Veglio, F., \& Milan, A. (2020). Hypertensive emergencies and urgencies in emergency departments: a systematic review and meta-analysis. Journal of 
Hypertension, Publish Ahead of Print.

https://doi.org/10.1097/hjh.0000000000002372

Bailey, J. E., Hajjar, M., Shoib, B., Tang, J., Ray, M. M., \& Wan, J. Y. (2014). Risk factors associated with antihypertensive medication nonadherence in a statewide Medicaid population. The American Journal of the Medical Sciences, 348(5), 410-415. https://doi.org/10.1097/MAJ.0b013e31825ce50f

Balakrishnan, M. P., Herndon, J. B., Zhang, J., Payton, T., Shuster, J., \& Carden, D. L. (2017). The Association of Health Literacy With Preventable Emergency Department Visits: A Cross-sectional Study. Acad Emerg Med, 24(9), 1042-1050. https://doi.org/10.1111/acem.13244

Bann, C. M., McCormack, L. A., Berkman, N. D., \& Squiers, L. B. (2012). The Health Literacy Skills Instrument: a 10-item short form. Journal of Health Communication, 17 Suppl 3, 191-202. https://doi.org/10.1080/10810730.2012.718042

Berkman, L. F., \& Syme, S. L. (1979). Social networks, host resistance, and mortality: a nine-year follow-up study of Alameda County residents. Am J Epidemiol, 109(2), 186-204. https://www.ncbi.nlm.nih.gov/pubmed/425958

Bobrow, K., Farmer, A. J., Springer, D., Shanyinde, M., Yu, L. M., Brennan, T., Rayner, B., Namane, M., Steyn, K., Tarassenko, L., \& Levitt, N. (2016). Mobile Phone 
Text Messages to Support Treatment Adherence in Adults With High Blood Pressure (SMS-Text Adherence Support [StAR]): A Single-Blind, Randomized Trial. Circulation, 133(6), 592-600.

https://doi.org/10.1161/CIRCULATIONAHA.115.017530

Brasseur, E., Gilbert, A., Servotte, J.-C., Donneau, A.-F., D’Orio, V., \& Ghuysen, A. (2020). Emergency department crowding: why do patients walk-in? Acta Clinica Belgica, 1-7.

Brody, A., Rahman, T., Reed, B., Millis, S., Ference, B., Flack, J. M., \& Levy, P. D. (2015). Safety and efficacy of antihypertensive prescription at emergency department discharge. Academic Emergency Medicine, 22(5), 632-635. https://doi.org/10.1111/acem.12660

Burnier, M., \& Egan, B. M. (2019). Adherence in hypertension: a review of prevalence, risk factors, impact, and management. Circulation research, 124(7), 1124-1140.

Census Bureau (U. S.). (2020). U.S. Census Bureau QuickFacts: Pemiscot County, Missouri. US Government. Retrieved May 15, 2020 from https ://www .census.gov/quickfacts/fact/table/pemiscotcountymissouri,MO/PST045219

Centers for Disease Control and Prevention (U.S.). (2016). High Blood Pressure Fact Sheet. Centers for Disease Control and Prevention. https: //www .cdc.gov/dhdsp/data_statistics/fact_sheets/fs_bloodpressure.htm 
Centers for Medicare and Medicaid Services. (2015a, October 5, 2015). CMS-1632-F and IFC, CMS-1632-CN2. Retrieved December 6, 2015 from https://www.cms.gov/Medicare/Medicare-Fee-for-ServicePayment/AcuteInpatientPPS/FY2016-IPPS-Final-Rule-Home-PageItems/FY2016-IPPS-Final-Rule$\underline{\text { Regulations.html} \text { ?DLPage }=1 \& D L E n t r i e s=10 \& D L S o r t=0 \& D L S o r t D i r=\text { ascending }}$

Centers for Medicare and Medicaid Services. (2015b, May 26, 2015). Readmission Reduction Measures Fact Sheet. Retrieved 4/13/2016 from https://www.qualitynet.org/dcs/BlobServer?blobkey=id\&blobnocache=true\&blob $\underline{\text { where }}=1228890460586 \&$ blobheader $=$ multipart $\% 2$ Foctetstream\&blobheadername $1=$ ContentDisposition\&blobheadervalue $1=$ attachment\%3Bfilename\%3DFY16_HRRP_Fact $\underline{\text { Sheet.pdf \&blobcol }=\text { urldata\&blobtable }=\text { MungoBlobs }}$

Cho, D. D., Austin, P. C., \& Atzema, C. L. (2015). Management of Discharged Emergency Department Patients with a Primary Diagnosis of Hypertension: A Multicentre Study. Canadian Journal of Emergency Medicine, 17(5), 523-531. https://doi.org/10.1017/cem.2015.36

Cohen, S. (1992). Stress, social support, and disorder. The meaning and measurement of social support, 109, 124. 
Cramer, J. A. (2004). A systematic review of adherence with medications for diabetes. Diabetes Care, 27(5), 1218-1224.

Cutler, D. M., \& Everett, W. (2010). Thinking outside the pillbox--medication adherence as a priority for health care reform. New England Journal of Medicine, 362(17), 1553-1555. https://doi.org/10.1056/NEJMp1002305

De Bleser, L., Dobbels, F., Berben, L., Vanhaecke, J., Verleden, G., Nevens, F., \& De Geest, S. (2011). The spectrum of nonadherence with medication in heart, liver, and lung transplant patients assessed in various ways. Transplant International, 24(9), 882-891. https://doi.org/10.1111/j.1432-2277.2011.01296.x

De Geest, S., Ruppar, T., Berben, L., Schönfeld, S., \& Hill, M. N. (2014). Medication non-adherence as a critical factor in the management of presumed resistant hypertension: a narrative.

Dibonaventura, M., Gabriel, S., Dupclay, L., Gupta, S., \& Kim, E. (2012). A patient perspective of the impact of medication side effects on adherence: results of a cross-sectional nationwide survey of patients with schizophrenia. $B M C$ Psychiatry, 12, 20. https://doi.org/10.1186/1471-244X-12-20

Dobbels, F., Berben, L., De Geest, S., Drent, G., Lennerling, A., Whittaker, C., \& Kugler, C. (2010). The psychometric properties and practicability of self-report 
instruments to identify medication nonadherence in adult transplant patients: a systematic review. Transplantation, 90(2), 205-219.

Dworkin, M. S., Chakraborty, A., Zychowski, D., Donenberg, G., Novak, R., \& Garofalo, R. (2018). Self-efficacy and ability to read as factors associated with antiretroviral therapy adherence in an HIV-infected population. International journal of STD \& AIDS, 29(12), 1154-1164.

Elwenspoek, M. M. C., Patel, R., Watson, J. C., \& Whiting, P. (2019). Are guidelines for monitoring chronic disease in primary care evidence based? $B M J, 365,12319$. https://doi.org/10.1136/bmj.12319

Esunge, P. M. (1991). From blood pressure to hypertension: the history of research. Journal of the Royal Society of Medicine, 84(10), 621. https://www.ncbi.nlm.nih.gov/pubmed/1744849

Fisher, W. A., Fisher, J. D., \& Harman, J. (2003). The information-motivation-behavioral skills model: A general social psychological approach to understanding and promoting health behavior. Social psychological foundations of health and illness, $82-106$.

G. Marazzi, G. C. F. P. S. Q. L. C. M. M. M. V. P. C. G. R. (2018). Bisoprolol Better Than Atenolol As Add On Therapy To Ace Inhibitors In Blood Pressure Control. Journal of Hypertension, 36. https://doi.org/10.1097/01.hjh.0000539074.54110.f7 
Ganguli, I., Shi, Z., Orav, E. J., Rao, A., Ray, K. N., \& Mehrotra, A. (2020). Declining use of primary care among commercially insured adults in the United States, 2008-2016. Annals of Internal Medicine.

Good, A. M., \& Driscoll, P. (2002). Clinical research in emergency medicine: putting it together. Emergency Medicine Journal, 19(3), 242-246. https://doi.org/10.1136/emj.19.3.242

Gorber, S. C., \& Tremblay, M. S. (2016). Self-Report and Direct Measures of Health: Bias and Implications. In R. J. Shephard \& C. Tudor-Locke (Eds.), The Objective Monitoring of Physical Activity: Contributions of Accelerometry to Epidemiology, Exercise Science and Rehabilitation (pp. 369-376). Springer International Publishing. https://doi.org/10.1007/978-3-319-29577-0_14

Guenther, W. (1977). Desk Calculation of Probabilities for the Distribution of the Sample Correlation Coefficient. The American Statistician, 31(1), 45-48.

Halladay, J. R., Donahue, K. E., Cene, C. W., Li, Q., Cummings, D. M., Hinderliter, A. L., Miller, C. L., Garcia, B. A., Little, E., Rachide, M., Tillman, J., Ammerman, A. S., \& DeWalt, D. (2017). The association of health literacy and blood pressure reduction in a cohort of patients with hypertension: The heart healthy lenoir trial. Patient education and counseling, 100(3), 542-549.

https://doi.org/10.1016/j.pec.2016.10.015 
Hunter, C. E., Palepu, A., Farrell, S., Gogosis, E., O'Brien, K., \& Hwang, S. W. (2014). Barriers to Prescription Medication Adherence Among Homeless and Vulnerably Housed Adults in Three Canadian Cities. Journal of primary care \& community health. https://doi.org/10.1177/2150131914560610

Ickovics, J. R., \& Meade, C. (2002). Adherence to HAART among patients with HIV: breakthroughs and barriers. AIDS Care, 14(3), 309-318.

Jaffe, T. A., Kocher, K. E., \& Ghaferi, A. A. (2018). Potentially Avoidable Emergency Department Use: When Policy Expects Patients to be Physicians. Annals of emergency medicine, 72(3), 256-258. https://doi.org/10.1016/j.annemergmed.2018.05.019

Jahagirdar, D., Kroll, T., Ritchie, K., \& Wyke, S. (2012). Using patient reported outcome measures in health services: A qualitative study on including people with low literacy skills and learning disabilities. BMC Health Services Research, 12(1), 431. https://doi.org/10.1186/1472-6963-12-431

Kale, M. S., Federman, A. D., Krauskopf, K., Wolf, M., O'Conor, R., Martynenko, M., Leventhal, H., \& Wisnivesky, J. P. (2015). The Association of Health Literacy with Illness and Medication Beliefs among Patients with Chronic Obstructive Pulmonary Disease. PLoS One, 10(4), e0123937.

https://doi.org/10.1371/journal.pone.0123937 
Kawachi, I., Colditz, G. A., Ascherio, A., Rimm, E. B., Giovannucci, E., Stampfer, M. J., \& Willett, W. C. (1996). A prospective study of social networks in relation to total mortality and cardiovascular disease in men in the USA. Journal of Epidemiology and Community Health, 50(3), 245-251.

https://doi.org/10.1136/jech.50.3.245

Kerr, T., Marshall, A., Walsh, J., Palepu, A., Tyndall, M., Montaner, J., Hogg, R., \& Wood, E. (2005). Determinants of HAART discontinuation among injection drug users. AIDS Care, 17(5), 539-549.

https://doi.org/10.1080/09540120412331319778

Khangura, D. S., Salam, M. W., Brietzke, S. A., \& Sowers, J. R. (2018). Hypertension in Diabetes. In Endotext [Internet]. MDText. com, Inc.

Kotchen, T. A. (2011). Historical trends and milestones in hypertension research: a model of the process of translational research. Hypertension, 58(4), 522-538. https://doi.org/10.1161/HYPERTENSIONAHA.111.177766

Li, J., \& Yun, S. (2013). Population with highest burden of high blood pressure in Missouri. Retrieved April 19 from http://health.mo.gov/living/healthcondiseases/chronic/heartandstroke/HighBloodP ressureInMissouriFactSheet.pdf 
Lin, M. P., Baker, O., Richardson, L. D., \& Schuur, J. D. (2018). Trends in Emergency Department Visits and Admission Rates Among US Acute Care Hospitals. Journal of the American Medical Association, Internal Medicine. https://doi.org/10.1001/jamainternmed.2018.4725

Lu, X., Juon, H.-S., He, X., Dallal, C. M., Wang, M. Q., \& Lee, S. (2019). The Association Between Perceived Stress and Hypertension Among Asian Americans: Does Social Support and Social Network Make a Difference? Journal of Community Health, 44(3), 451-462. https://doi.org/10.1007/s10900-018-00612$\underline{7}$

Marcum, Z. A., Zheng, Y., Perera, S., Strotmeyer, E., Newman, A. B., Simonsick, E. M., Shorr, R. I., Bauer, D. C., Donohue, J. M., Hanlon, J. T., \& Health, A. B. C. S. (2013). Prevalence and correlates of self-reported medication non-adherence among older adults with coronary heart disease, diabetes mellitus, and/or hypertension. Research in Social and Administrative Pharmacy, 9(6), 817-827. https://doi.org/10.1016/j.sapharm.2012.12.002

Matsumura, K., Arima, H., Tominaga, M., Ohtsubo, T., Sasaguri, T., Fujii, K., Fukuhara, M., Uezono, K., Morinaga, Y., Ohta, Y., Otonari, T., Kawasaki, J., Kato, I., Tsuchihashi, T., \& Comfort, I. (2013). Impact of antihypertensive medication adherence on blood pressure control in hypertension: The COMFORT study. QJM: An International Journal of Medicine, 106(10), 909-914. https://doi.org/10.1093/qjmed/hct121 
Mazer, M., Bisgaier, J., Dailey, E., Srivastava, K., McDermoth, M., Datner, E., \& Rhodes, K. V. (2011). Risk for cost-related medication nonadherence among emergency department patients. Academic Emergency Medicine, 18(3), 267-272. https://doi.org/10.1111/j.1553-2712.2011.01007.x

McCarthy, M. L., Ding, R., Roderer, N. K., Steinwachs, D. M., Ortmann, M. J., Pham, J. C., Bessman, E. S., Kelen, G. D., Atha, W., Retezar, R., Bessman, S. C., \& Zeger, S. L. (2013). Does providing prescription information or services improve medication adherence among patients discharged from the emergency department? A randomized controlled trial. Annals of emergency medicine, 62(3), 212-223 e211. https://doi.org/10.1016/j.annemergmed.2013.02.002

Menzin, J., Boulanger, L., Friedman, M., Mackell, J., \& Lloyd, J. R. (2014). Treatment adherence associated with conventional and atypical antipsychotics in a large state Medicaid program. Psychiatric Services.

Meurer, W. J., Dome, M., Brown, D., Delemos, D., Oska, S., Gorom, V., \& Skolarus, L. (2019). Feasibility of Emergency Department-initiated, Mobile Health Blood Pressure Intervention: An Exploratory, Randomized Clinical Trial. Academic Emergency Medicine, 26(5), 517-527. https://doi.org/10.1111/acem.13691

Mill, J. G. (2019). Social Determinants of Hypertension. Arquivos Brasileiros de Cardiologia, 113, 696-698. 
http://www.scielo.br/scielo.php?script=sci_arttext\&pid=S0066$\underline{782 X 2019001000696 \& n r m=i s o}$

Mozaffarian, D., Benjamin, E. J., Go, A. S., Arnett, D. K., Blaha, M. J., Cushman, M., Das, S. R., de Ferranti, S., Després, J.-P., Fullerton, H. J., Howard, V. J., Huffman, M. D., Isasi, C. R., Jiménez, M. C., Judd, S. E., Kissela, B. M., Lichtman, J. H., Lisabeth, L. D., Liu, S., Mackey, R. H., Magid, D. J., McGuire, D. K., Mohler, E. R., Moy, C. S., Muntner, P., Mussolino, M. E., Nasir, K., Neumar, R. W., Nichol, G., Palaniappan, L., Pandey, D. K., Reeves, M. J., Rodriguez, C. J., Rosamond, W., Sorlie, P. D., Stein, J., Towfighi, A., Turan, T. N., Virani, S. S., Woo, D., Yeh, R. W., \& Turner, M. B. (2015). Heart Disease and Stroke Statistics-2016 Update. A Report From the American Heart Association. https://doi.org/10.1161/cir.0000000000000350

Mutter, R., \& Clancy, C. (2014). Investing in emergency medicine to improve health care for all Americans: the role of the Agency for Healthcare Research and Quality. Annals of emergency medicine, 63(5), 580-583.

https://doi.org/10.1016/j.annemergmed.2013.06.021

Nadia Hatmi, Z. (2019). Future Direction of Emergency Medicine Research; Can We Overcome the Difficulties and Fill in Knowledge Gaps? Advanced Journal of Emergency Medicine, 3(1), e1. https://doi.org/10.22114/AJEM.v3i1.120 
Nakhutina, L., Gonzalez, J. S., Margolis, S. A., Spada, A., \& Grant, A. (2011).

Adherence to antiepileptic drugs and beliefs about medication among predominantly ethnic minority patients with epilepsy. Epilepsy Behavior, 22(3), 584-586. https://doi.org/10.1016/j.yebeh.2011.08.007

Neter, E., \& Brainin, E. (2019). Association Between Health Literacy, eHealth Literacy, and Health Outcomes Among Patients With Long-Term Conditions. European Psychologist, 24(1), 68-81. https://doi.org/10.1027/1016-9040/a000350

Nyaaba, G. N., Stronks, K., Meeks, K., Beune, E., Owusu-Dabo, E., Addo, J., de-Graft Aikins, A., Mockenhaupt, F., Bahendeka, S., Klipstein-Grobusch, K., Smeeth, L., \& Agyemang, C. (2019). Is social support associated with hypertension control among Ghanaian migrants in Europe and non-migrants in Ghana? The RODAM study. Internal and Emergency Medicine, 14(6), 957-966.

https://doi.org/10.1007/s11739-019-02075-7

O'Conor, R., Wolf, M. S., Smith, S. G., Martynenko, M., Vicencio, D. P., Sano, M., Wisnivesky, J. P., \& Federman, A. D. (2015). Health literacy, cognitive function, proper use, and adherence to inhaled asthma controller medications among older adults with asthma. Chest, 147(5), 1307-1315. https://doi.org/10.1378/chest.14$\underline{0914}$

Oras, P., Habel, H., Skoglund, P. H., \& Svensson, P. (2020). Elevated Blood Pressure in the Emergency Department: A Risk Factor for Incident Cardiovascular Disease. 
Hypertension, 75(1), 229-236.

https://doi.org/10.1161/HYPERTENSIONAHA.119.14002

Overgaauw, N., Alsma, J., Brink, A., Hameli, E., Bahmany, S., Peeters, L. E. J., Van Den Meiracker, A. H., Schuit, S. C. E., Koch, B. C. P., \& Versmissen, J. (2019). Drug nonadherence is a common but often overlooked cause of hypertensive urgency and emergency at the emergency department. Journal of Hypertension, 37(5), 1048-1057. https://doi.org/10.1097/HJH.0000000000002005

Ozemek, C., Tiwari, S., Sabbahi, A., Carbone, S., \& Lavie, C. J. (2020). Impact of therapeutic lifestyle changes in resistant hypertension. Progress in cardiovascular diseases, 63(1), 4-9.

Padhy, M., Lalnuntluangi, R., Chelli, K., \& Padiri, R. A. (2016). Social Support and Adherence among Hypertensive Patients. AJHM, 1, 33-40.

Pantell, M., Rehkopf, D., Jutte, D., Syme, S. L., Balmes, J., \& Adler, N. (2013). Social Isolation: A Predictor of Mortality Comparable to Traditional Clinical Risk Factors. American Journal of Public Health, 103(11), 2056-2062. https://doi.org/10.2105/ajph.2013.301261

Papademetriou, V., Andreadis, E., \& Geladari, C. (2018). Management of Hypertension. Springer Link. https://doi.org/10.1007/978-3-319-92946-0 
Pellowski, J. A., \& Kalichman, S. C. (2016). Health behavior predictors of medication adherence among low health literacy people living with HIV/AIDS. Journal of Health Psychology, 21(9), 1981-1991.

https://doi.org/10.1177/1359105315569617

Polit, D. F., \& Beck, C. T. (2020). Nursing research: Generating and assessing evidence for nursing practice (9th ed.). Wolters Kluwer.

Prendergast, H. M., Colla, J., Del Rios, M., Marcucci, J., Schulz, R., \& O'Neal, T. (2015). Playing a role in secondary prevention in the ED: Longitudinal study of patients with asymptomatic elevated blood pressures following a brief education intervention: A pilot study. Public Health, 129(5), 604-606. https://doi.org/10.1016/j.puhe.2015.02.001

Roebuck, M. C., Liberman, J. N., Gemmill-Toyama, M., \& Brennan, T. A. (2011). Medication adherence leads to lower health care use and costs despite increased drug spending. Health Affairs, 30(1), 91-99. https://doi.org/10.1377/hlthaff.2009.1087

Rummel-Kluge, C., Komossa, K., Schwarz, S., Hunger, H., Schmid, F., Kissling, W., Davis, J. M., \& Leucht, S. (2012). Second-generation antipsychotic drugs and extrapyramidal side effects: a systematic review and meta-analysis of head-tohead comparisons. Schizophrenia bulletin, 38(1), 167-177. 
Saladini, F., Mancusi, C., Bertacchini, F., Spannella, F., Maloberti, A., Giavarini, A., Rosticci, M., Bruno, R. M., Pucci, G., Grassi, D., Pengo, M., \& Muiesan, M. L. (2020). Diagnosis and treatment of hypertensive emergencies and urgencies among Italian emergency and intensive care departments. Results from an Italian survey: Progetto GEAR (Gestione dell'Emergenza e urgenza in ARea critica). European Journal of Internal Medicine, 71, 50-56. https://doi.org/10.1016/j.ejim.2019.10.004

Saleh, A., \& Bista, K. (2017). Examining Factors Impacting Online Survey Response Rates in Educational Research: Perceptions of Graduate Students. Journal of multidisciplinary evaluation, 13(29), 12.

Sampson, A., Briggs, L., Hunt, E., McCarty, S., Mawson, A., Coe, B. L., Leisman, J., Schofield, J., Bartlett, D., Epperly, K., Harmon, L., Huff, M., Karhoff, L., McGhee, M., McIlhenny, B., McNeely, J., Pezley, G., Shaw, A., Stark, A., Stone, R., Thompson, K., \& Williams, N. (2017). Emergency Department Super-Utilizer Project MUHC 2017 Sharing Days, Columbia MO.

Sawkin, M. T., Deppe, S. J., Thelen, J., Stoner, S. C., Dietz, C. A., \& Rasu, R. S. (2015). Health Literacy and Medication Adherence Among Patients Treated in a Free Health Clinic: A Pilot Study. Health Services Research and Managerial Epidemiology, 2. https://doi.org/10.1177/2333392815589094 
Schafer-Keller, P., Steiger, J., Bock, A., Denhaerynck, K., \& De Geest, S. (2008).

Diagnostic accuracy of measurement methods to assess non-adherence to immunosuppressive drugs in kidney transplant recipients. American Journal of

Transplant Medicine, 8(3), 616-626. https://doi.org/10.1111/j.1600$\underline{6143.2007 .02127 . x}$

Shallcross, A. J., Butler, M., Tanner, R. M., Bress, A. P., Muntner, P., Shimbo, D., Ogedegbe, G., Sims, M., \& Spruill, T. M. (2017). Psychosocial correlates of apparent treatment-resistant hypertension in the Jackson Heart Study. Journal of Human Hypertension, 31(7), 474-478. https://doi.org/10.1038/jhh.2016.100

Sinagra, E., Perricone, G., D'Amico, M., Tinè, F., \& D'Amico, G. (2014). Systematic review with meta-analysis: the haemodynamic effects of carvedilol compared with propranolol for portal hypertension in cirrhosis. Alimentary Pharmacology \& Therapeutics, 39(6), 557-568. https://doi.org/doi:10.1111/apt.12634

Smith, J. E., \& Morley, R. (2015). The emergency medicine research priority setting partnership. Emergency Medicine Journal, 32(11), 830. https://doi.org/10.1136/emermed-2015-205353

Spikes, T., Higgins, M., Quyyumi, A., Reilly, C., Pemu, P., \& Dunbar, S. (2019). The Relationship Among Health Beliefs, Depressive Symptoms, Medication Adherence, and Social Support in African Americans With Hypertension. Journal 
of Cardiovascular Nursing, 34(1), 44-51.

https://doi.org/10.1097/jen.0000000000000519

Stolzmann, K., Meterko, M., Miller, C. J., Belanger, L., Seibert, M. N., \& Bauer, M. S. (2019). Survey Response Rate and Quality in a Mental Health Clinic Population: Results from a Randomized Survey Comparison. The Journal of Behavioral Health Services \& Research, 46(3), 521-532. https://doi.org/10.1007/s11414-018$\underline{9617-8}$

Stone, V. E., Hogan, J. W., Schuman, P., Rompalo, A. M., Howard, A. A., Korkontzelou, C., \& Smith, D. K. (2001). Antiretroviral regimen complexity, self-reported adherence, and HIV patients' understanding of their regimens: survey of women in the her study. JAIDS Journal of Acquired Immune Deficiency Syndromes, 28(2), 124-131.

Strickland, J. C., \& Stoops, W. W. (2018). Feasibility, acceptability, and validity of crowdsourcing for collecting longitudinal alcohol use data. Journal of the experimental analysis of behavior, 110(1), 136-153.

Swales, J. D. (1996). A century of Arterial Hypertension 1896-1996. Journal of the Royal Society of Medicine, 89(11), 658-658. https://www.ncbi.nlm.nih.gov/pmc/articles/PMC1296015/

https://www.ncbi.nlm.nih.gov/pmc/PMC1296015/ 
The SPRINT Research Group. (2015). A Randomized Trial of Intensive versus Standard Blood-Pressure Control. New England Journal of Medicine, 373(22), 2103-2116. https://doi.org/10.1056/NEJMoa1511939

Thurston, M. M., Bourg, C. A., Phillips, B. B., \& Huston, S. A. (2015). Impact of health literacy level on aspects of medication nonadherence reported by underserved patients with type 2 diabetes. Diabetes Technology \& Therapeutics, 17(3), 187193. https://doi.org/10.1089/dia.2014.0220

Tocci, G., Presta, V., \& Volpe, M. (2020). Hypertensive crisis management in the emergency room: time to change? Journal of Hypertension, 38(1), 33-34. https://doi.org/10.1097/HJH.0000000000002235

Toy, E. L., Beaulieu, N. U., McHale, J. M., Welland, T. R., Plauschinat, C. A., Swensen, A., \& Duh, M. S. (2011). Treatment of COPD: relationships between daily dosing frequency, adherence, resource use, and costs. Respiratory medicine, 105(3), 435441. https://doi.org/10.1016/j.rmed.2010.09.006

Tyser, A. R., Abtahi, A. M., McFadden, M., \& Presson, A. P. (2016). Evidence of nonresponse bias in the Press-Ganey patient satisfaction survey. BMC Health Services Research, 16(1), 350. https://doi.org/10.1186/s12913-016-1595-z

Vollbrecht, M., Biese, K., Hastings, S. N., Ko, K. J., \& Previll, L. A. (2018). SystemsBased Practice to Improve Care Within and Beyond the Emergency Department. 
Clinics in Geriatric Medicine, 34(3), 399-413.

https://doi.org/10.1016/j.cger.2018.04.005

Wald, N., Wald, D., \& Kellermann, A. L. (2018). When Guidelines Cause Hypertension. The American journal of medicine. https://doi.org/10.1016/j.amjmed.2018.06.007

Wallbach, M., Lach, N., Stock, J., Hiller, H., Mavropoulou, E., Chavanon, M.-L., Neurath, H., Blaschke, S., Lowin, E., Herrmann-Lingen, C., Müller, G. A., \& Koziolek, M. J. (2019). Direct assessment of adherence and drug interactions in patients with hypertensive crisis-A cross-sectional study in the Emergency Department. The Journal of Clinical Hypertension, 21(1), 55-63. https://doi.org/10.1111/jch.13448

Wannasirikul, P., Termsirikulchai, L., Sujirarat, D., Benjakul, S., \& Tanasugarn, C. (2016). Health Literacy, Medication Adherence, and Blood Pressure Level among Hypertensive Older Adults Treated at Primary Health Care Centers. Southeast Asian Journal of Tropical Medicine and Public Health, 47(1), 109-120. https://www.ncbi.nlm.nih.gov/pubmed/27086432

Whelton, P. K., Carey, R. M., Aronow, W. S., Casey, D. E., Jr., Collins, K. J., Dennison Himmelfarb, C., DePalma, S. M., Gidding, S., Jamerson, K. A., Jones, D. W., MacLaughlin, E. J., Muntner, P., Ovbiagele, B., Smith, S. C., Jr., Spencer, C. C., Stafford, R. S., Taler, S. J., Thomas, R. J., Williams, K. A., Sr., Williamson, J. D., \& Wright, J. T., Jr. (2017). 2017 
ACC/AHA/AAPA/ABC/ACPM/AGS/APhA/ASH/ASPC/NMA/PCNA Guideline for the Prevention, Detection, Evaluation, and Management of High Blood Pressure in Adults: A Report of the American College of Cardiology/American Heart Association Task Force on Clinical Practice Guidelines. Hypertension. https://doi.org/10.1161/HYP.0000000000000065

Wu, F., \& Sheng, Y. (2019). Social support network, social support, self-efficacy, healthpromoting behavior and healthy aging among older adults: A pathway analysis. Archives of Gerontology and Geriatrics, 85, 103934. https://doi.org/https://doi.org/10.1016/j.archger.2019.103934

Yannoutsos, A., Dreyfuss Tubiana, C., Safar, M. E., \& Blacher, J. (2017). Optimal blood pressure target in stroke prevention. Current Opinion in Neurology, 30(1), 8-14. https://doi.org/10.1097/wco.0000000000000407

Zhang, Z.-Y., Asayama, K., Franklin, S. S., Thijs, L., \& Staessen, J. A. (2019). Cardiovascular Events and Mortality in White Coat Hypertension. Annals of Internal Medicine, 171(8), 602-603. 
Benjamin Lloyd Coe was born July 19, 1981 in Independence, MO to parents Barton Lloyd, and Barbara Ann Sprague. Benjamin was raised in Blue Springs, MO with his two younger brothers David Allen, and Matthew Adam. Benjamin was educated in Blue Springs public schools, graduating from Blue Springs High School in 1999 with general honors.

Benjamin began attending the University of Missouri - Columbia in August 1999, initially graduating undergraduate in 2004 with dual Bachelor of Science degrees in Biological Sciences and Medicinal Chemistry. He would go on to complete a Masters of Arts degree in Biological Sciences with an emphasis in Reproductive Biology in May of 2006.

Benjamin returned to undergraduate education and completed a Bachelor of Science in Nursing from University of Missouri - Columbia's Sinclair School of Nursing in 2011. He joined the Air Force Reserve in August 2013, serving as an Emergency Trauma nurse with the 932d Medical Squadron at Scott Air Force Base, Illinois, where he currently holds the rank of Captain. While working full time as a nurse at University Hospital Emergency Department and serving his country, Benjamin returned to graduate school to complete a Doctor of Philosophy of Nursing in Summer of 2014. While completing school, Benjamin has maintained full time employment status with the University of Missouri, served honorably with the United States Air Force, and served his local community volunteering as a Fire Fighter, and eventually Lieutenant with The Boone County Fire Protection District. Benjamin also volunteers his summers in service to youth by working as a Camp Nurse and Paramedic at H. Roe Bartle Scout Reservation each summer. 
Benjamin places high value in the promotion of his profession. He is an active and engaged member of the Emergency Nurses Association. Benjamin has attended multiple National Conferences. He is active on the local, state, and national levels. Having served as an officer at both the local and state level as well as serving on multiple professional advisory boards at a national level. He also attends nurse-lobbying events at both state and national levels working with members of congress to ensure that Emergency Nurses have the resources that they need to be successful in caring for the most vulnerable of patients.

Lastly, as a lifelong learner, Benjamin values certification and dedication to his field. During his nursing career, Benjamin has tested for and maintains five nursing specialty certifications demonstrating his professionalism and dedication to the field. 